\title{
Functional interaction between Env oncogene from Jaagsiekte sheep retrovirus and tumor suppressor Sprouty2
}

\author{
Ebenezer Chitra ${ }^{1,2}$, Yi-Wen Lin ${ }^{1,5}$, Fabian Davamani ${ }^{2}$, Kuang-Nan Hsiao ${ }^{1}$, Charles Sia', Shih-Yang Hsieh',
} Olivia L Wei ${ }^{3}$, Jen-Hao Chen ${ }^{4}$, Yen-Hung Chow ${ }^{1 *}$

\begin{abstract}
Background: Jaagsiekte sheep retrovirus (JSRV) is a type D retrovirus capable of transforming target cells in vitro and in vivo. The Envelope (Env) gene from JSRV and from related retroviruses can induce oncogenic transformation, although the detailed mechanism is yet to be clearly understood. Host cell factors are envisaged to play a critical determining role in the regulation of Env-mediated cell transformation.

Results: JSRV Env-mediated transformation of a lung adenocarcinoma cell line induced rapid proliferation, anchorage-independent growth and tumor formation, but completely abrogated the migration ability. An analysis of the signaling scenario in the transformed cells suggested the involvement of the ERK pathway regulated by Sprouty2 in cell migration, and the PI3K-Akt and STAT3 pathways in proliferation and anchorage-independence. On the other hand, in a normal lung epithelial cell line, Env-mediated transformation only decreased the migration potential while the other functions remained unaltered. We observed that Env induced the expression of a tumor suppressor, Sprouty2, suggesting a correlation between Env-effect and Sprouty2 expression. Overexpression of Sprouty2 per se not only decreased the migratory potential and tumor formation potential of the target cells but also made them resistant to subsequent Env-mediated transformation. On the other hand, over expression of the functional mutants of Sprouty2 had no inhibitory effect, confirming the role of Sprouty2 as a tumor suppressor.

Conclusions: Our studies demonstrate that Env and Sprouty2 have a functional relationship, probably through shared signaling network. Sprouty2 functions as a tumor suppressor regulating oncogenic transformation of cells, and it therefore has the potential to be exploited as a therapeutic anti-cancer agent.
\end{abstract}

\section{Background}

The Envelope proteins of many retroviruses have been identified to be directly involved in oncogenic transformation of cells leading to the evolution of a new paradigm. Friend Spleen Focus Forming Virus (SFFV) was the first virus to be identified to be linked to oncogenesis induced by a retroviral Env protein [1]. Tumor formation by SFFV was reported to involve the mitogenactivated protein kinase (MAPK) and the phosphatidylinositol 3-kinase (PI3K) pathways, with a number of host factors governing the susceptibility to tumor formation [1]. Structural proteins of Avian Hemangioma Virus

\footnotetext{
* Correspondence: choeyenh@nhri.org.tw
${ }^{1}$ Vaccine R\&D Center, National Health Research Institutes, 35, Keyan Road,

* Correspondence: choeyenh@nhri.org.tw
'Vaccine R\&D Center, National Health Research Institutes, 35, Keyan Road, Zhunan, Miaoli County 350, Taiwan
}

(c) 2010 Chitra et al; licensee BioMed Central Ltd. This is an Open Access article distributed under the terms of the Creative Commons Attribution License (http://creativecommons.org/licenses/by/2.0), which permits unrestricted use, distribution, and reproduction in any medium, provided the original work is properly cited. have also been shown to be involved in oncogenic transformation [1]. Env genes from Jaagsiekte sheep retrovirus (JSRV) and Enzootic Nasal Tumor Virus (ENTV) are both known to act as oncogenes. They can transform cell lines in vitro, using similar set of signaling pathways involving the MAPK and PI3K, and when expressed in vivo they can induce tumors in animals [2-4]. Detailed investigation of the retroviral Env genes could reveal the underlying mechanisms and signaling pathways implicated in oncogenic transformation.

JSRV is an acutely transforming betaretrovirus that induces contagious pulmonary adenocarcinoma in sheep [5] which resembles a subtype of human adenocarcinoma [6]. The Env oncogene of JSRV is capable of transforming target cells in vivo as well as in vitro, 
acting through the PI3K/Akt and MAPK signaling pathways $[3,7-10]$. The JSRV Envelope protein harbors a putative binding site for the p85 regulatory subunit of PI3K in its cytoplasmic tail [11], and the amino acid Y590 present at this site is envisaged to play a crucial role in tumorigenesis [12]; mutation of this amino acid has been reported to reduce the transformation efficiency of Envelope [13,14]. The surface domain of JSRV Envelope protein is capable of activating an independent signaling pathway leading to the transformation of target cells [15]. Induction of the PI3K/Akt pathway is considered essential for Env-mediated cellular transformation [13]. However, in some cell types, Env-mediated transformation induced the MAPK pathway [8], suggesting that both the PI3K and MAPK pathways can be modulated by Env. Development of lung tumors has been reported by lung-specific expression of Env gene in transgenic [16] or normal mice [3], confirming its role as an oncogene.

Cell growth control networks involve oncoproteinand tumor suppressor protein-regulated signaling pathways with increasingly diverse functions and complex interactions for each set of proteins. While some oncoprotein-tumor suppressor pairs like $\mathrm{Mdm} 2$ and $\mathrm{p} 53$ [17], mixed lineage leukemia protein and menin [18], MSP58 and PTEN [19] are capable of direct physical interaction, other cryptic indirect interactions are yet to be unraveled. This study focuses on the functional interaction between the Env oncogene of Jaagsiekte sheep retrovirus (JSRV) and the tumor suppressor, human Sprouty2.

The Sprouty family comprises of non-autonomous signaling proteins that function in feedback circuits involving the Ras/MAP kinase pathway $[20,21]$ and act as tumor suppressors. Sprouty was first discovered in Drosophila [22], and later its isoforms were identified in many organisms. Human Sprouty 2 is a $35 \mathrm{kDa}$ polypeptide known to associate with a wide range of signaling molecules like c-Cbl [23], human Seven in Absentia homolog 2 (SIAH2) [24], protein phosphatase 2A (PP2A) [25] and the adaptor protein, CrkL [26] by means of its key tyrosine residue Y55, which is tyrosine phosphorylated upon stimulation $[27,28]$. Sprouty2 can bind to Grb2 through the SH3 binding motif in the Cterminus [25]. It can also bind to Shp2 phosphatase [29], Raf1 and Tesk1 via the cysteine rich domain (CRD) [30,31]. Human Sprouty2 is known to inhibit cell migration and proliferation in response to serum and growth factors [32]. When overexpressed, it is capable of inhibiting anchorage-independent cell growth, cell migration and invasion [33], tumor growth and metastasis [34]. Like most tumor suppressors, the expression of Sprouty is downregulated in many cancers such as breast cancer [35], prostate cancer [36,37], liver cancer
$[38,39]$, non-small cell lung cancer [40] and B-cell lymphomas [41] by variable mechanisms depending on the individual cancer type.

Our study indicates that the biochemical status of the cell plays a crucial role in determining its susceptibility to oncogenic transformation. We have identified a novel relationship between the tumor suppressor Sprouty2 and the Env oncogene in vitro, both signaling through overlapping pathways. Overexpression of Sprouty2 seems to inhibit the oncogenic transformation induced by Env, resulting in suppressed tumor formation potential. We found that amino acid Y55 is crucial for Sprouty2 function.

\section{Results and Discussion}

\section{Env-mediated transformation induces Sprouty2 and} inhibits cell migration

To analyze the in vitro transformation induced by JSRV Env gene in normal as well as the cancer cell lines derived from human lung, the full length $E n v$ gene from JSRV was cloned in pBluescript vector under control of the CMV promoter and used for transfection of the lung adenocarcinoma cell line A549 and the immortalized lung epithelial cell line BEAS-2B. An analysis of the genes transiently induced by Env in A549 cells three and six days post transfection showed upregulation of the tumor suppressor Sprouty2 when analyzed by semi-quantitative RT-PCR using different template concentrations (Figure 1A). This novel phenomenon of an oncogene upregulating a tumor suppressor was not observed in BEAS-2B cells transiently transfected with the Env gene (data not shown). Regulation of the expression of Sprouty2 in the cells occurs at multiple levels [42], and therefore the exact reason for increased Sprouty2 expression in A549-Env could not be ascertained. We assumed that the upregulation of Sprouty2 might be a standby effect in the course of modulation of cell signaling network by Env. We created stable cell lines overexpressing Sprouty2 as well as stable Envtransformed cell lines. The expression level of Sprouty2 mRNA in these cell lines was ascertained by quantitative RT-PCR. The results revealed that A549-Spr had 2.9fold increased amount of Sprouty2 transcripts while A549-Env had a 6-fold increase in Sprouty2 levels compared to A549 (Figure 1B). On the other hand, BEAS2B-Env cell line had only 2.9-fold increase in the expression of Sprouty 2 mRNA compared to BEAS-2B (Figure 1C). These findings support our theory that Sprouty2 induction has a positive correlation to Envmediated transformation.

In addition to Sprouty2, another candidate tumor suppressor HYAL2, was also found to be induced by Envmediated transformation of A549 cells (data not shown); the tumor suppressor activity of HYAL2 is reported to be 
A

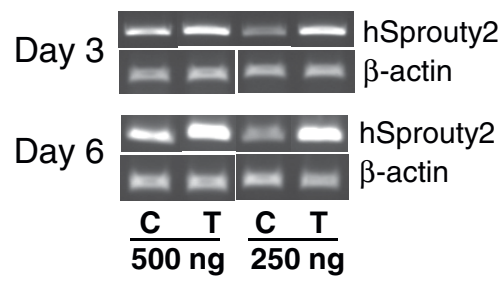

B

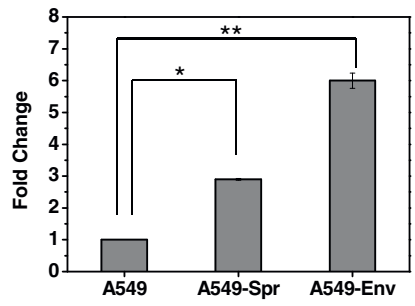

C

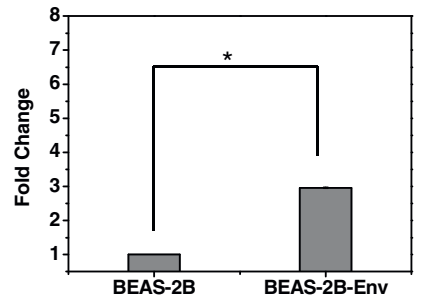

D

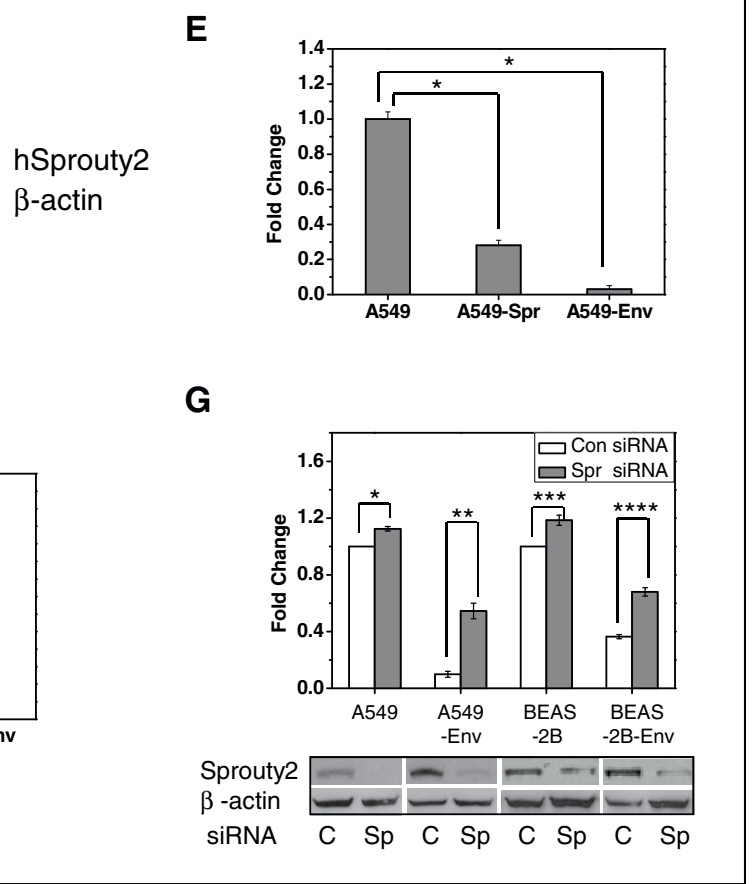

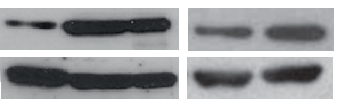

A549 A549 A549 BEAS BEAS -Env -Spr - $B$ B

$\mathbf{F}$

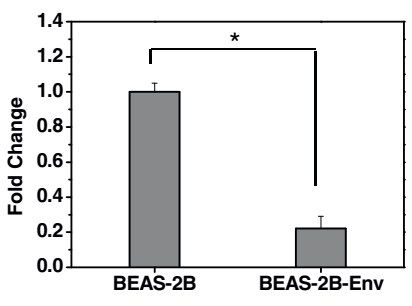

Figure 1 Induction of Sprouty2 and inhibition of cell migration in JSRV Env transformed cells. (A) A549 cells were transfected with a plasmid carrying JSRV Env gene (T) or the empty vector (C), and the expression of Sprouty2 and $\beta$-actin was monitored on days 3 and 6 post transfection by RT-PCR using different template concentrations (500 ng and $250 \mathrm{ng}$ ). Data represent two independent experiments. (B) and (C) Quantitative RT-PCR analysis depicting the fold increase in Sprouty2 mRNA levels in the stable cell lines A549-Spr and A549-Env compared to A549 $\left({ }^{*} P<0.0007\right.$, $\left.{ }^{*} P<0.0001\right)$ (B) and in BEAS-2B-Env compared to BEAS-2B (C) ${ }^{*} P<0.0001$. (D) Western blot analysis of the expression of Sprouty2 protein and $\beta$-actin in stably transformed cell lines compared to the parental cell lines. Data represent five independent experiments. (E) and (F) Cell migration assay: Equal number of A549, A549-Spr and A549-Env cells (E) or BEAS-2B and BEAS-2B-Env cells (F) were allowed to migrate across the $8 \mu \mathrm{m}$ porous membrane in a Boyden chamber in response to serum. After $15 \mathrm{~h}$, the migrated cells were fixed, stained and counted ( $\left.{ }^{\mathrm{P}}<0.0001\right)$. (G) The effect of 200 pmoles of Sprouty2-specific siRNA on the migration ability of A549, A549-Env, BEAS-2B and BEAS-2BEnv cells compared to control siRNA $\left({ }^{*} P=0.014,{ }^{* *} P=0.0169,{ }^{* * *} P=0.034,{ }^{* * * *} P=0.0111\right)$. Corresponding changes in Sprouty 2 protein levels compared to $\beta$-actin control are depicted in the Western blot shown below the bar diagram for the respective cell lines. (C) indicates control siRNA and (Sp) indicates Sprouty2 siRNA. Data represent two independent experiments. 
inhibited by JSRV Env [43]. Although usually oncogenes are known to suppress or inactivate tumor suppressors, some tumor suppressors are known to be recruited for oncogene-induced functions such as DNA damage [44], and some proteins like SnoN are identified to function as an oncogene as well as a tumor suppressor [45].

The functional relationship between the oncogenes and the tumor suppressors is therefore multifaceted, and we went ahead to study the correlation between JSRV Env oncogene and Sprouty 2 tumor suppressor. An analysis of Sprouty 2 protein levels in the stable cell lines revealed a significant upregulation in A549-Spr and A549-Env compared to A549, and in BEAS-2B-Env compared to BEAS-2B (Figure 1D). We deduced that the increased expression of Sprouty2 might have significant physiological ramifications and went ahead to test this hypothesis.

Overexpression of Sprouty2 is known to interfere with cell migration and invasion [33]. So, the migration ability of the cell lines under study was compared by allowing them to migrate across a porous membrane in a Boyden chamber. A549 cells per se exhibited high migration potential which was reduced by $\sim 70 \%$ in A549-Spr, while A549-Env cells were unable to migrate (Figure 1E). Similarly, BEAS-2B cells had good migration capability whereas BEAS-2B-Env cells exhibited $\sim 80 \%$ reduction in their migration potential (Figure 1F). The effect of $E n v$-transformation on the migration ability was drastic in A549-Env cells abrogating their migration potential, whereas in BEAS-2B-Env cells, the effect was severe resulting in reduced migration ability. Therefore, we hypothesize that Sprouty2 might have a hand in the compromised migration potential of these cells.

To verify the role of Sprouty2 in the regulation of cell migration, A549, A549-Env, BEAS-2B and BEAS-2B-Env cells were treated with 200 pmoles of siRNA for Sprouty2 or with control siRNA and then allowed to migrate. It was observed that siRNA-mediated inhibition of Sprouty2 expression resulted in a corresponding enhancement in cell motility (Figure 1G). The enhancement was more prominent in A549-Env and BEAS-2BEnv cells that had higher levels of Sprouty2 initially and consequently very low migration potential. Inhibition of Sprouty2 expression in the cells enhanced their migration ability, thereby confirming that Sprouty2 played an inhibitory role in cell migration.

To investigate in detail the physiological consequences brought about by Env and Sprouty2, further investigations were carried out.

\section{Env induces proliferation and colony formation in A549- Env}

Proliferation and invasion are two distinct fundamental components occupying opposing ends of a spectrum in malignant cells and are not necessarily displayed by the same cells. Invasion, migration and branching morphogenesis are exclusive characteristics of highly invasive cells while highly proliferative cells are highly tumorigenic and display anchorage-independent growth in soft agar [46]. Anchorage-independent growth is an attribute of oncogenic transformation by Env that causes cells to loose contact inhibition resulting in the formation of distinct foci in culture [47]. The cell lines were further investigated for their proliferation potential and anchorage-independent growth.

A549-Env had a higher proliferation rate with $\sim 4$-fold more cells after 96 hours than A549 and A549-Spr; increased proliferation being a characteristic feature of oncogene-induced transformation (Figure 2A). On the other hand, both BEAS-2B and BEAS-2B-Env had comparable proliferation rates (Figure $2 \mathrm{~B}$ ). Our results clearly demonstrate that the loss of invasive ability induced by JSRV Env is distinct from the enhanced proliferation function. Env-mediated transformation had converted the highly invasive A549 cells into highly proliferative A549-Env cells. Our results suggest that the choice of invasion versus proliferation and tumor formation functions is more likely to be governed by distinct pathways of signaling, which are probably evoked independently.

In colony formation assay, A549-Env cells formed a number of distinct, large colonies in soft agar in 12 days, a characteristic feature of JSRV Env-mediated transformation (Figure 2C). A549-Spr showed inhibition of colony formation, probably due to the inhibitory effect of Sprouty2, as reported earlier [33]. A549, although known to be capable of anchorage-independent growth, could form only very small colonies by day 12 , probably owing to its lower proliferation rate compared to A549-Env. It is clear that Env had induced higher proliferation rate and colony formation in A549-Env cells in spite of high levels of Sprouty2. Both BEAS-2B and BEAS-2B-Env could not form colonies in soft agar suggesting that Env transformation had less effect in the normal epithelial cell line BEAS-2B.

BEAS-2B cells are immortalized human lung epithelial cells that have low transfection efficiency [48], and the reproducibility of transformation assays is reported to be difficult [49]. Therefore it is not surprising that Envmediated transformation of BEAS-2B could induce only limited biochemical and physiological alterations. In an attempt to unravel the underlying mechanisms responsible for Env-mediated transformation, an analysis of the status of signaling molecules in these cell lines was carried out.

\section{In vivo tumorigenesis is inhibited by Sprouty2, but enhanced by Env}

To investigate the in vivo tumor forming potential, A549, A549-Spr, A549-Env, BEAS-2B or BEAS-2B-Env cells 


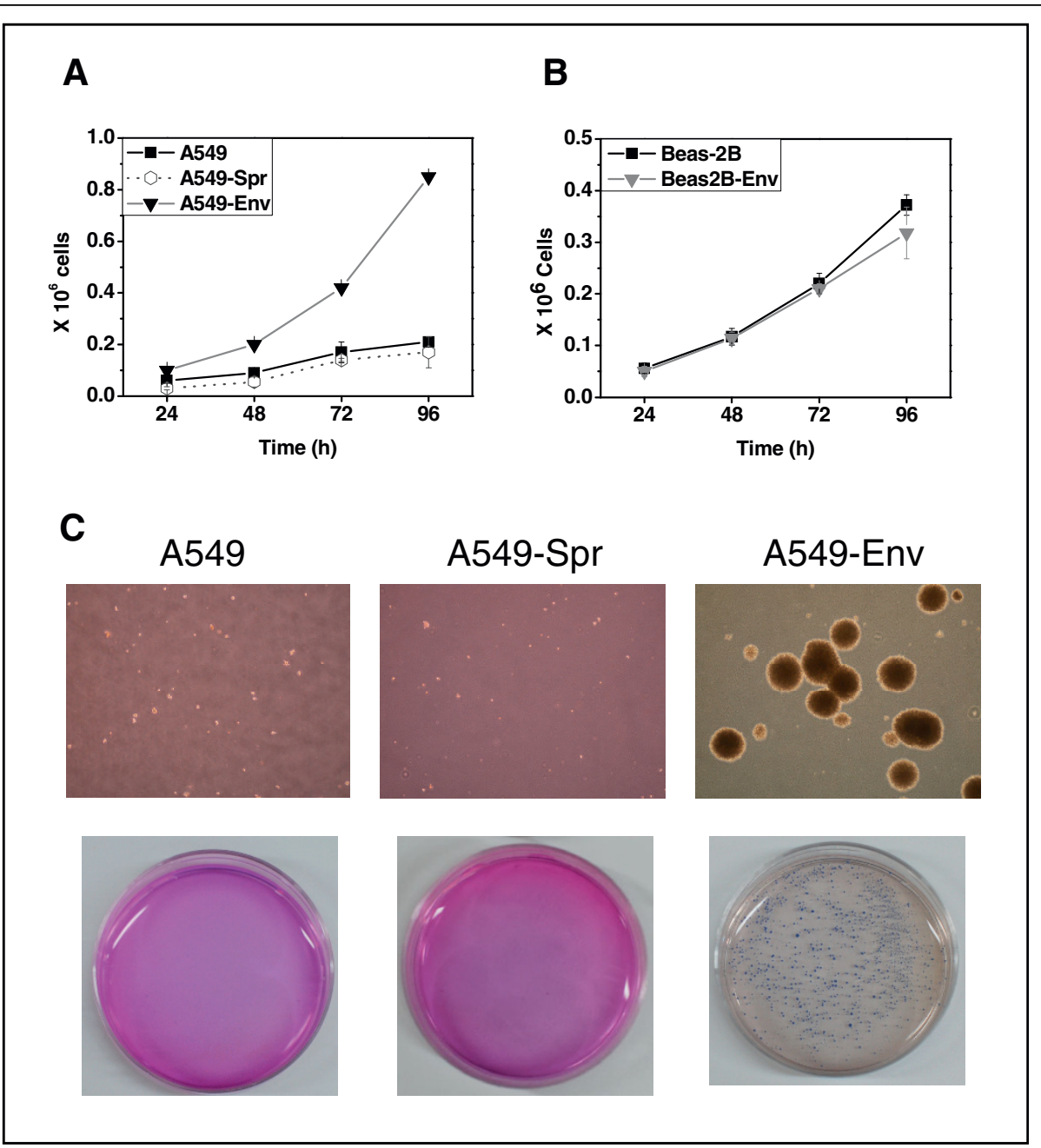

Figure 2 JSRV Env induces proliferation and colony formation in A549-Env cells. (A and B) Equal number $\left(1 \times 10^{5}\right.$ cells/well) of A549, A549-Spr and A549-Env cells (A) or BEAS-2B and BEAS-2B-Env cells (B) were allowed to proliferate for four days and live cells were counted every 24 h. (C) A549, A549-Spr and A549-Env cells were cultured in soft agar to assess their anchorage-independent colony formation ability. The colonies were counted and photographed on day 12 .

were injected subcutaneously into SCID mice and allowed to form tumors. A549 was capable of forming tumors in vivo while the tumor forming potential was decreased in A549-Spr that overexpresses the tumor suppressor Sprouty2 (Figure 3A). A549-Env was capable of forming massive tumors, characteristic of oncogenic transformation. All the tumors had pushing margins rather than invading margins at the time of termination of the experiment, and in vivo invasiveness was not detected.

The growth rate of tumors as indicated by the progressive increase in tumor volume (Figure 3B) as well as tumor weight (Figure 3C) was the greatest in A549-Env $(\sim 2.3 \mathrm{~g})$ and the lowest in A549-Spr ( 0.1 g) compared to A549 ( 0.8 g) (Figure 3B and 3C). The inhibitory effect of overexpressed Sprouty2 in tumor formation that has been reported earlier [34] is confirmed by our observations.

All the tumors were sectioned and stained with hematoxylin and eosin and the presence of proliferating tumor cells was confirmed (Figure 3D). The sections showed a poorly differentiated adenocarcinoma composed of cells with hyperchromatic nuclei. The tumor formed by A549-Env showed increased cellularity owing to the high proliferation rate of A549-Env cells. BEAS-2B and BEAS-2B-Env failed to form tumors in SCID mice, behaving more like normal epithelial cells without much permanent alterations in their functionality. An analysis of the signaling scenario in these cell types gave an insight into their biochemical attributes. 


\section{A A549 A549-Spr A549-Env}

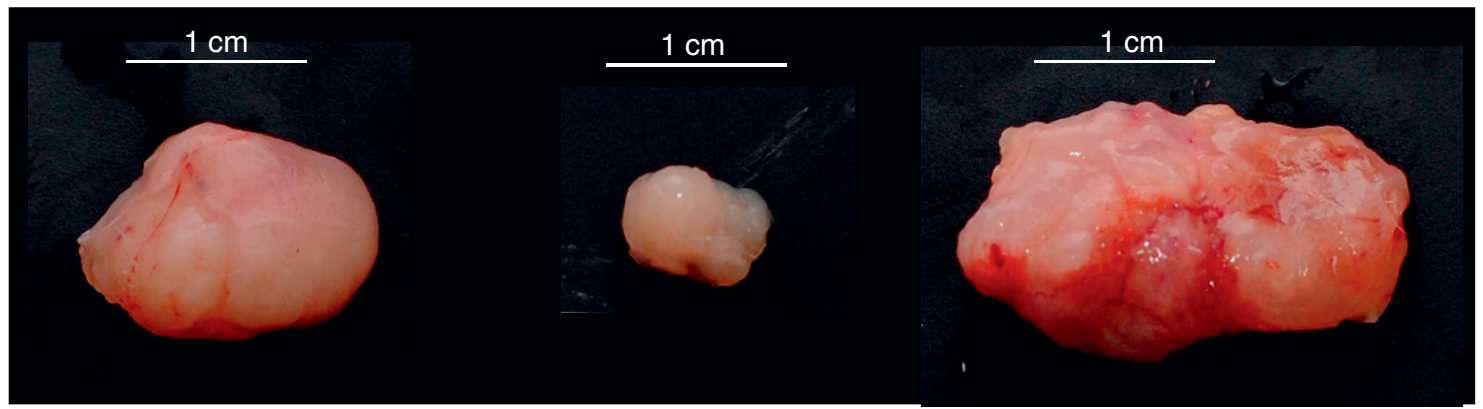

B

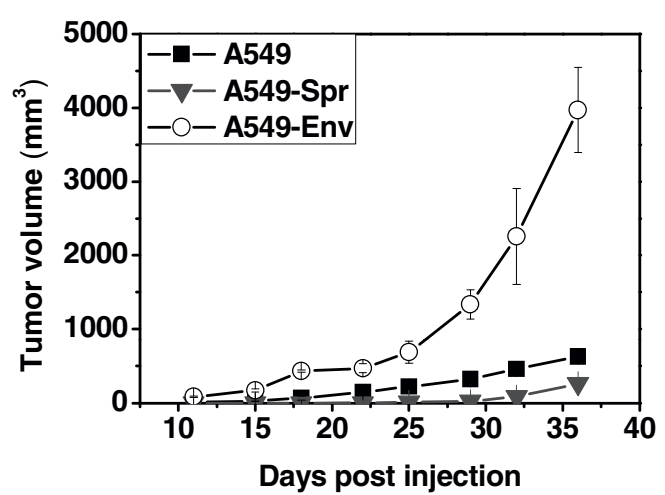

C

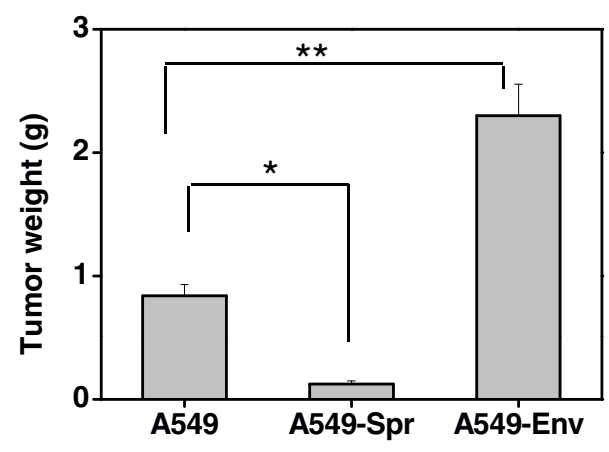

D
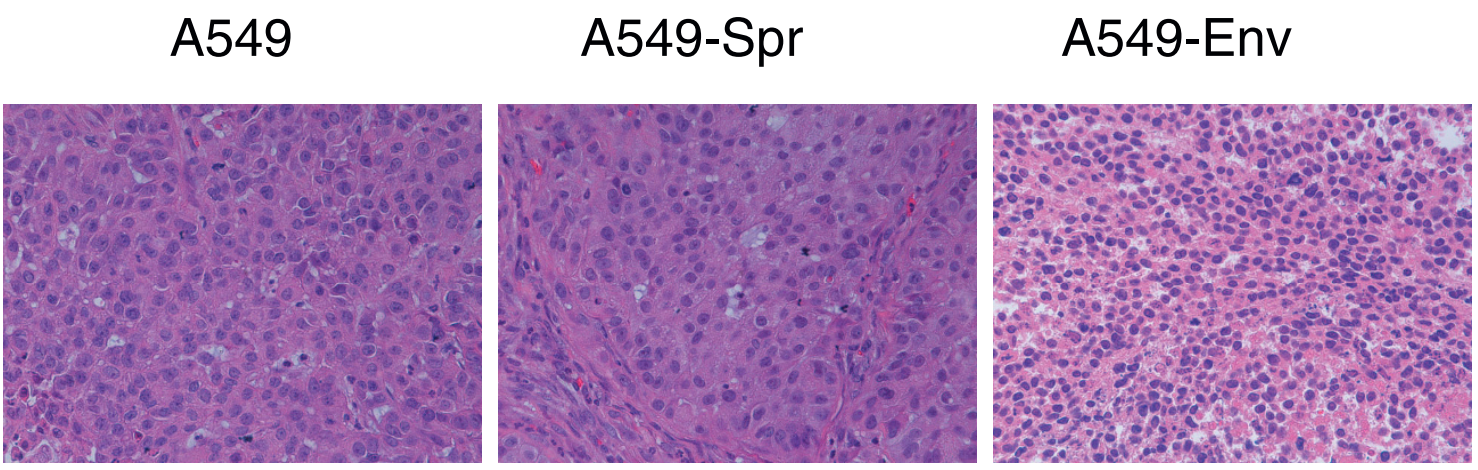

Figure 3 Env enhances and Sprouty2 inhibits tumor formation in SCID mice. (A) Pictures of in vivo tumors formed by A549, A549-Spr and A549-Env cells injected into the subcutaneous tissue of SCID mice (5-7 mice per group) and excised on day 34. (B) The growth rate of tumors formed by the respective cell lines in SCID mice is represented as increase in tumor volume monitored for up to 5 weeks. (C) Average weight of tumors resected from SCID mice 34 days after injection ( ${ }^{*} P=0.0003,{ }^{* * P}=0.0006$ ). (D) Hematoxylin and eosin (H\&E) staining of sections of xenografts resected from SCID mice to confirm the presence of malignant cells. Magnification 400x. 
Alteration of the signaling network by Env and Sprouty2 Characterization of the molecular pathways leading to cancer is a major step towards understanding and combating the disease [50]. The alterations induced by Sprouty2 and Env in the signaling scenario of A549 were investigated by Western blot. The mechanism of JSRV Env-mediated transformation of cells is not clear and is reported to modulate the PI3K and MAPK pathways [48]. Sprouty proteins are feedback negative regulators of the ERK pathway [51] that is thought to regulate cell invasion [52,53]. Upon analysis, A549 was found to have high levels of phosphor-ERK; A549-Spr had very low levels; and in A549-Env, phosphor-ERK was not detected (Figure 4A). Similarly, BEAS-2B had high levels of phosphor-ERK, which was decreased in BEAS-2BEnv. These observations are consistent with the increased expression of Sprouty2 in the respective transformed cell lines compared to their parental counterparts.

TWIST is a transcription factor that has been detected in various carcinomas and is suggested to enhance the invasive and metastatic ability of cancer cells [54-56]. The expression of TWIST was significantly reduced in A549-Env and BEAS-2B-Env compared to A549 and BEAS-2B respectively (Figure $4 \mathrm{~A}$ ). These observations are consistent with the decreased migration potential of A549-Env and BEAS-2B-Env.

The p38 MAPK pathway is reported to have anti- or pro- proliferative functions depending on the levels of kinase activity and the interplay between all the signaling pathways [57]. Phosphorylation of p38 MAPK was decreased in A549-Spr compared to A549, but was significantly enhanced in A549-Env, probably owing to Env-induced signaling. However, in BEAS-2B, the phosphorylation of p38 MAPK was high, which was not seen in BEAS-2B-Env (Figure 4A). The implication of signaling mediated by p38 MAPK in BEAS-2B cells is not clear.

The PI3K/Akt pathway is known to play a crucial role in cell proliferation and survival and shows a high frequency of alterations in cancer [58,59]. Akt phosphorylation was marginally increased in A549-Spr compared to A549. But, A549-Env had very high levels of phosphor-Akt, showing a positive correlation with the observed high proliferation rate (Figure 4A). Similarly, BEAS-2B-Env showed an increase in the phosphorylation of Akt compared to BEAS-2B, consistent with the reported involvement of PI3K/Akt pathway in Envinduced transformation [13], although the proliferation rate of all the BEAS-2B cell lines remained similar.

The tumor suppressor phosphatase and tensin homologue (PTEN) is a negative regulator of the PI3K/Akt pathway [60] that can suppress cell growth and tumor formation [61,62]. Active PTEN was lower in A549-Env cells compared to A549 and A549-Spr or to the inactive phosphor-PTEN level (Figure 4A). In BEAS-2B and BEAS-2B-Env, PTEN and phospho PTEN levels were high and comparable, consistent with their inability to form tumors.

The transcription factor STAT3 is hypothesized to play a role in anchorage-independence [63] and cell growth [64]. In A549-Env, high levels of phosphorSTAT3 were detected both in the nucleus and the cytoplasm, indicating over activation, consistent with the increased growth and colony forming potential of the cells (Figure 4B). In A549 that is capable of anchorageindependent growth, phospho STAT3 was detected in the nucleus. But in A549-Spr, BEAS-2B and BEAS-2BEnv, all of which are impaired in anchorage-independent colony formation, phospho STAT3 level in the nuclear fraction was very low (Figure 4B). Increased activation of Akt, STAT3 and reduced expression of PTEN and TWIST are likely to have contributed to the high proliferation and colony formation potential of A549-Env.

Matrix metalloproteinases (MMPs) are enzymes that are involved in the breakdown of the extracellular matrix abetting invasion and metastasis of cancer cells [65]. Tissue inhibitors of metalloproteinases (TIMPs) are inhibitors of MMPs, which decrease cell migration [66]. Usually the MMP/TIMP ratio (MMP2/TIMP2 and MMP9/TIMP1) determines the invasiveness of the cells and is known to be altered in many cancers [67]. To address the role of MMPs and TIMPs in altering the migration ability of the cell lines under study, the activity of MMPs was evaluated by gelatin zymogram and the amount of TIMPs by Western blot. MMP levels were high, and TIMP levels were very low in A549, an invasive cell line (Figure 4C and 4D). In A549-Env, MMP2 level was relatively less, and MMP9 was hardly detectable while TIMP levels remained high, consistent with its reduced migration potential (Figure 4C and 4D). A549-Spr, in spite of having similar levels of MMPs and TIMPs like A549-Env, had less activity in the cell migration assay (Figure 1E). In BEAS-2B and BEAS-2B-Env, the levels of MMPs and TIMPs were low and comparable (data not shown). Elevated TIMPs and decreased MMP9 levels seem to have contributed to the decreased migration efficiency of A549-Spr and A549-Env. Overall, the signaling status of the cells is consistent with the manifested functions in the respective cell lines.

\section{$\mathrm{PI3K} / \mathrm{Akt}$ and ERK pathways regulate proliferation and cell migration}

The MAPK (p44/42) and Akt pathways have been implicated in JSRV Env-mediated transformation in many cell types $[8,48]$. Since the ERK and PI3K/Akt pathways appear to be involved in cell migration and proliferation respectively in A549 cells, in order to confirm the same, 


\section{A}
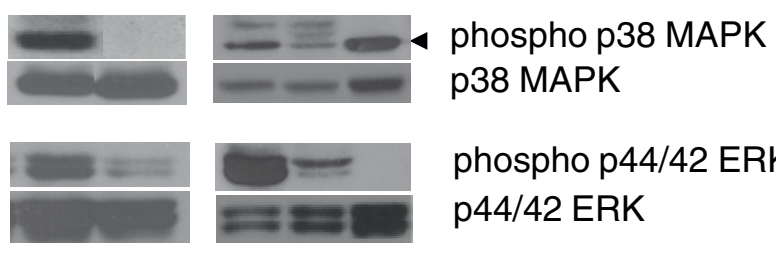

phospho p44/42 ERK

p44/42 ERK
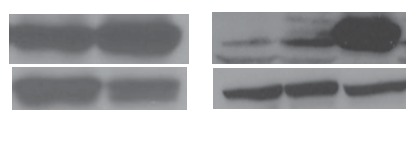

phospho Ser473 Akt
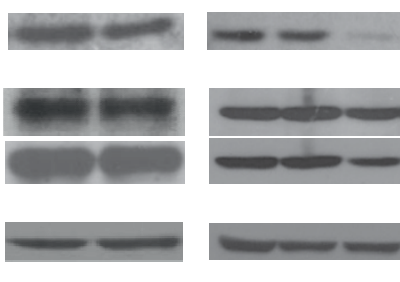

Akt

Twist

BEAS BEAS- A549 A549 A549

-2B 2B-Env $\quad$-Spr -Env

B
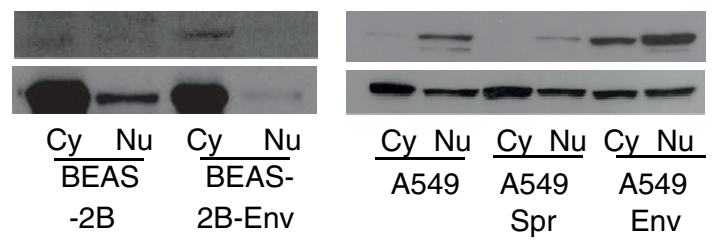

\section{phospho STAT3}

STAT3

phospho PTEN

PTEN

$\beta$-actin

$-2 \mathrm{~B}$

2B-Env

C

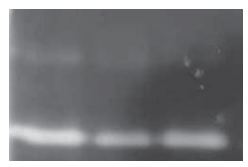

A549 A549 A549

-Spr -Env
MMP9

MMP2

D

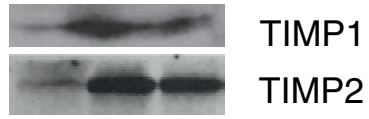

A549 A549 A549

-Spr - Env

Figure 4 Alteration of signal transduction by Env and Sprouty2. (A) Cell lysates were prepared by homogenization of A549, A549-Spr, A549Env, BEAS-2B and BEAS-2B-Env cells. The proteins were separated on $10 \%$ acrylamide gel, transferred to nitrocellulose membrane and probed with various antibodies. The results show the levels of phospho p38 MAPK, p38 MAPK, phospho p44/42 ERK, p44/42 ERK, phospho Ser473 Akt, Akt, TWIST, phospho PTEN, PTEN and $\beta$-actin in the indicated cell lines. (B) Proteins were extracted from cytoplasmic (cy) and nuclear (nu) fractions of the cells and the levels of phospho STAT3 and STAT3 were ascertained by Western blot. (C) MMP Zymogram: Conditioned media obtained from the cell lines was assayed for gelatinase activity using 10\% SDS-PAGE gel to estimate MMP activity. (D) Conditioned media obtained from the cell lines was concentrated; the secreted proteins were separated by SDS-PAGE and immunoblotted with antibodies against TIMP1 and TIMP2.

we treated the cells with pharmacological inhibitors of the respective pathways to study their effect on invasion and proliferation.

A549 and BEAS-2B cells are intrinsically invasive and responded differently to the inhibitors of ERK and PI3K.
The migration ability of A549 cells was reduced in the presence of either of the MEK inhibitors, U0126 or PD98059 while the PI3K inhibitor LY294002 had no effect (Figure 5A). This observation confirms that the ERK pathway is required for cell migration in A549. 
A

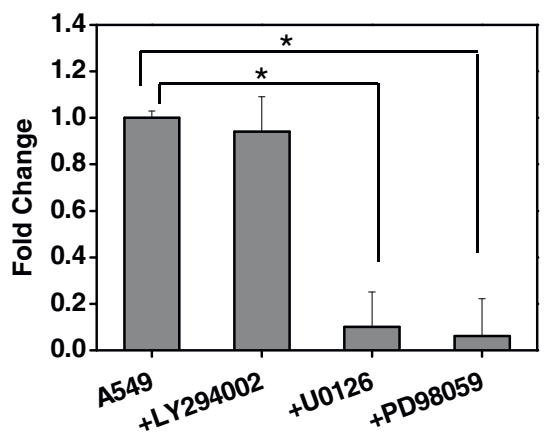

B

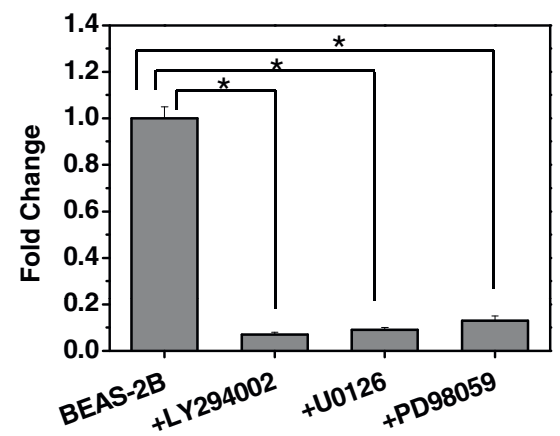

C

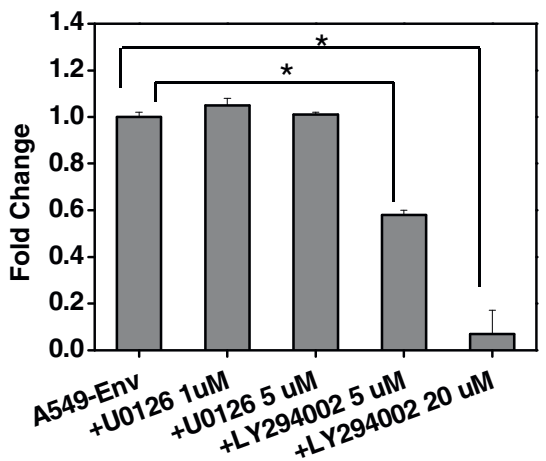

Figure 5 ERK and PI3K pathways regulate cell migration and proliferation. A549 (A) or BEAS-2B (B) cells were allowed to migrate across the $8 \mu \mathrm{m}$ porous membrane in a Boyden chamber either alone or in the presence of PI3K inhibitor LY294002 (20 MM) or MEK inhibitors U0126 $(20 \mu \mathrm{M})$ or PD98059 $(20 \mu \mathrm{M})$ in response to serum. After $15 \mathrm{~h}$, the migrated cells were fixed, stained and counted. (A) ${ }^{*} \mathrm{P}<0.0001$; (B) ${ }^{*} \mathrm{P}<0.0003$ ). (C) A549-Env cells were allowed to proliferate either alone or in the presence of MEK inhibitor U0126 (1 $\mu \mathrm{M})$ or $(5 \mu \mathrm{M})$ or PI3K inhibitor LY294002 (5 $\mu \mathrm{M})$ or $(20 \mu \mathrm{M})$. Data shown represent proliferation at $72 \mathrm{~h}$. $\left({ }^{*} \mathrm{P}<\right.$ $0.0001)$.
This also suggests that the reduced migration ability of A549-Spr and A549-Env might be due to the inhibition of the ERK pathway probably caused by the upregulation of Sprouty2. Inhibition of the p44/42 MAPK pathway by pharmacological inhibitors is known to abolish JSRV Env-mediated transformation of cells in vitro [8] confirming that this pathway is involved in oncogenic transformation caused by Env.

On the other hand, in BEAS-2B cells, the MEK inhibitors as well as the PI3K inhibitor were able to inhibit cell migration (Figure 5B). In BEAS-2B, multiple pathways seem to function in an overlapping manner and therefore a single pathway could not be attributed to a particular physiological function. BEAS-2B-Env cells do not have enhanced proliferation rate and therefore further investigation for attribution of pathway specificity to proliferation was conducted using A549-Env cells.

Akt pathway is highly enhanced in A549-Env cells and therefore is correlated with its very high proliferation potential. When A549-Env cells were allowed to proliferate in the presence of MEK inhibitors or PI3K inhibitor, only the latter (LY294002) was able to inhibit proliferation, confirming that the PI3K/Akt pathway is required for their enhanced proliferation potential (Figure $5 \mathrm{C}$ ). Our observations suggest that the Akt pathway is involved in proliferation and the ERK pathway in migration of A549 and its derivative cell lines.

\section{The amino acids Y55 and Y227 are crucial for the function of Sprouty2}

Our observations implicate that Sprouty2 has the potential to alter the physiology of A549 and therefore further investigations on the tumor suppressive functions of Sprouty2 were conducted using A549. To ascertain the role of Sprouty2 in inhibiting cell migration, tumor formation and anchorage-independent growth, functional mutants of Sprouty 2 were created. Two key tyrosine residues, Y55 and Y227 have been identified in human Sprouty2 protein, mutations of which seem to affect its interaction with the other signaling molecules as well as its function as an ERK inhibitor. Y55 residue is the major tyrosine crucial for the function of Sprouty2, in the absence of which, Y227 can mediate some of its functions $[27,68,69]$. We created two mutants of Sprouty2 - Y55F and Y227F by site-directed mutagenesis and expressed them in A549 cells to create 'A549-Y55FSpr' and 'A549-Y227FSpr' stable cell lines respectively. The mutants are envisaged to interrupt the functions of endogenous Sprouty2.

Functional analysis revealed that while both A549Y55FSpr and A549-Y227FSpr cells were capable of anchorage-independent colony formation, the former was more potent causing an increase in colony size 
A

A549

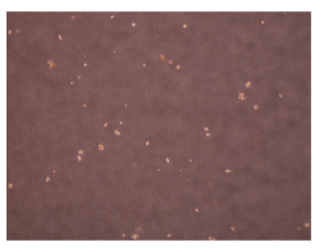

A549-

Y55FSpr

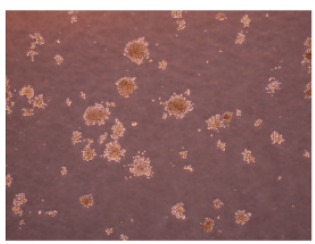

B

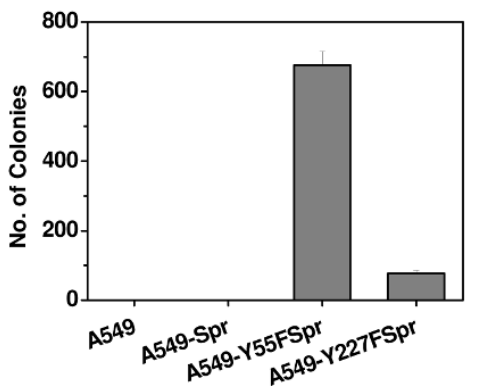

D

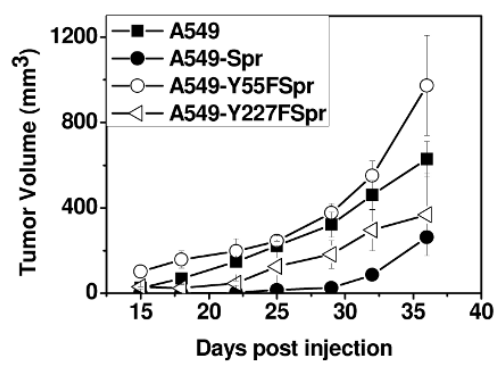

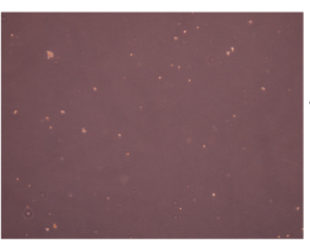

A549-Spr

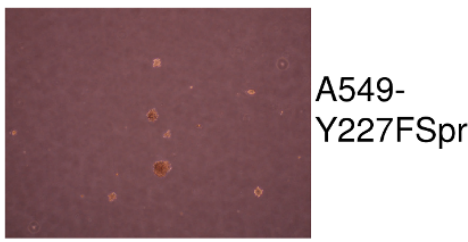

C

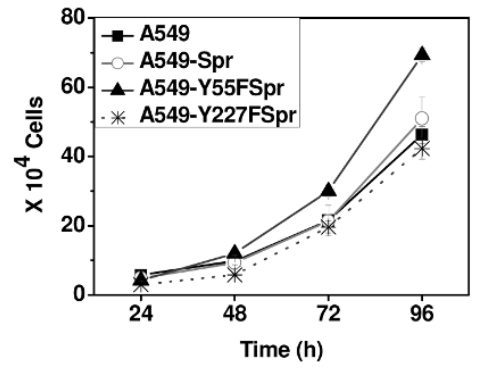

E

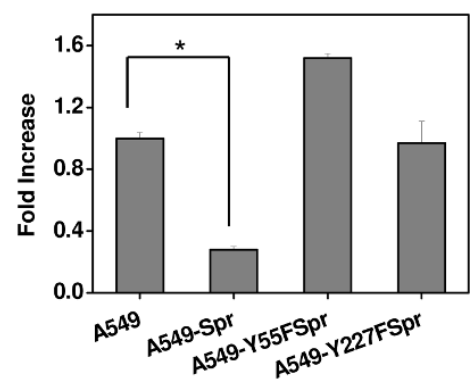

$\mathbf{F}$

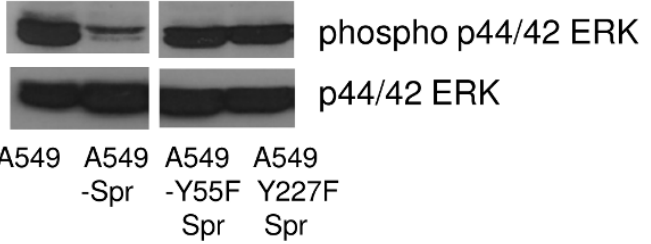

Figure 6 Tyrosine mutants of Sprouty2 inhibit its tumor suppressive function. Stable transfectants of A549 over expressing either Y55F or Y227F mutant of Sprouty2 designated A549-Y55FSpr and A549-Y227FSpr respectively were created and assayed for their functional properties. (A) and (B) Colony formation assay: A549, A549-Y55FSpr and A549-Y227FSpr cells were cultured in soft agar to assess their anchorageindependent colony formation ability. (A) The colonies were counted and photographed on day 12. (B) Graphical representation of the number of colonies formed by each cell line. (C) Equal numbers $\left(1 \times 10^{5}\right.$ cells/well) of A549, A549-Y55FSpr and A549-Y227FSpr cells were allowed to proliferate for four days. Schematic representation of their proliferation rate represented by live cell count every $24 \mathrm{~h}$. (D) In vivo tumor formation: A549, A549-Spr or A549-Y55FSpr or A549-Y227FSpr cells were injected into the subcutaneous tissue of SCID mice. Growth rate of tumors formed by the respective cell lines in SCID mice is represented as increase in tumor volume monitored for up to 5 weeks. (E) Migration assay: Cells were allowed to migrate across the $8 \mu \mathrm{m}$ porous membrane in a Boyden chamber in response to serum. After $15 \mathrm{~h}$, the migrated cells were fixed, stained and counted. $\left({ }^{*} \mathrm{P}=0.0029\right)$. (F) Western blot analysis of the cell lysates of A549, A549-Spr, A549-Y55FSpr and A549Y227FSpr to check for the levels of phospho ERK p44/42 and total ERK p44/42. 
(Figure 6A) as well as colony number compared to A549 (Figure 6B). A549-Y227FSpr formed smaller and fewer colonies than A549-Y55FSpr. The proliferation rate of A549-Y55FSpr was higher than that of A549 while A549-Y227FSpr was comparable to A549 (Figure 6C). These observations corroborate the finding that Y55 is the major tyrosine residue crucial for Sprouty2 function.

When these cells were injected into SCID mice subcutaneously to compare the tumor forming potential, it was observed that the tumor growth rate of A549Y55FSpr was marginally greater than that of A549, while A549-Y227FSpr had a tumor growth rate less than A549, but greater than A549-Spr (Figure 6D).

The effect of the functional mutants of Sprouty 2 on cell migration was investigated. A549-Y55FSpr had 1.5-fold increased migration potential than A549 while the migration potential of A549-Y227FSpr was comparable to that of A549 (Figure 6E). These observations confirm the inhibitory effect of the tyrosine mutants on endogenous Sprouty2 function and the inhibitory role of Sprouty2 in tumorigenesis, anchorage-independence and migration. These data also confirm that Tyr55 plays a more significant role in Sprouty2 function than Tyr227 and therefore is more effective in disrupting the function of endogenous Sprouty2.

An analysis of the alteration of signaling network in these cell lines revealed that ERK phosphorylation was not inhibited in both A549-Y55FSpr and A549Y227FSpr, whereas inhibition of ERK phosphorylation is a characteristic feature of A549-Spr (Figure 6F). The profile of other signaling molecules such as Akt, p38 MAPK, STAT3, and PTEN in A549 transfected with the mutants was similar to that of A549 (data not shown). Based on these observations we assume that the major inhibitory effect of wild type Sprouty 2 is due to its inhibition of the ERK pathway.

\section{Overexpression of Sprouty2 makes cells resistant to Env- mediated transformation}

To study the correlation between Sprouty2 and the viral oncogene Env, A549-Spr and BEAS-2B-Spr cells overexpressing Sprouty2 were transfected with a plasmid carrying Env gene to allow the formation of distinct foci, a hall mark of Env-induced transformation. Fourteen days after transformation with Env, A549 cells showed a number of large distinct foci (A549 + Env) while very few small foci were seen in A549-Spr (A549-Spr + Env) (Figure 7). Similarly, BEAS-2B developed distinct foci upon transformation with Env (BEAS-2B + Env) while in BEAS-2B-Spr (BEAS-2B-Spr + Env), foci formation was not observed (Figure 7). Env and Sprouty2 both seem to affect transformation of target cells, with Env promoting it and Sprouty2 antagonizing it. BEAS-2BSpr had decreased migration rate and decreased phosphor- ERK levels compared to BEAS-2B (data not shown), but otherwise, both the cell lines were comparable in terms of their functionality and the status of signaling molecules. Interference of foci formation in BEAS-2B-Spr and A549-Spr cells indicates that Sprouty2 inhibits Env-mediated transformation.

A549-Spr cells transfected with Env (A549-Spr-Env) had similar rates of proliferation and migration like A549-Spr and were unable to form colonies in soft agar (data not shown). When injected into SCID mice, their tumor forming potential was only marginally enhanced than that of A549-Spr in terms of tumor size (Figure 8A and $8 \mathrm{~B}$ ) and tumor weight (Figure $8 \mathrm{C}$ ). Env was therefore unable to endow rapid proliferation and tumor formation potential to A549-Spr cells. These results indicate that overexpression of Sprouty2 in both A549 and BEAS-2B cells that are normally susceptible to Envmediated transformation, had made them resistant to the same. This can be attributed to the overexpression of the tumor suppressor Sprouty 2 and subsequent alterations in the physiological and signaling status of the cells.

Oncogenesis results from changes in kinetics or abundance of proteins in signal transduction networks with the control dispersed over many components. While the MAPK and PI3K pathways are crucial for Env to induce transformation and proliferation, Sprouty 2 also has some connections to these pathways. The effect of Sprouty2 (wild type as well as Y55F or Y227F mutants) and Env on the major signaling elements and their effect on the functional outcomes of different cells are depicted in Figure 9. Sprouty proteins are well documented to be feedback negative regulators of the MAPK pathway $[20,21]$. Sprouty2 is reported to bind to phosphatidylinositol-4, 5-biphosphate, a substrate for PI3K by means of its translocation domain [70]. Mouse Sprouty4 is reported to have an inhibitory effect on Akt phosphorylation [71]. Therefore, resistance to Env by modulation of PI3K pathway by Sprouty2 is a possibility and can not be ruled out. We could not identify any direct interaction between Env and Sprouty2 proteins (data not shown), as has been documented for many oncoproteintumor suppressor protein pairs. Multiple oncoproteins and tumor suppressor proteins have been found to act through the same signaling pathway, to cause or prevent cellular transformation [72]. Similarly, Env and Sprouty2 might affect the same signaling pathways in either a synergistic or antagonistic manner. Parallel Ras/MAPK and PI3K pathways with common connections $[73,74]$ are known to exist in many scenarios. We therefore propose dual regulation of the PI3K/Akt and ERK pathways by both Env and Sprouty2, thereby constituting a functional cross talk. We propose that Sprouty2 resists Envmediated transformation by modulating the signaling 


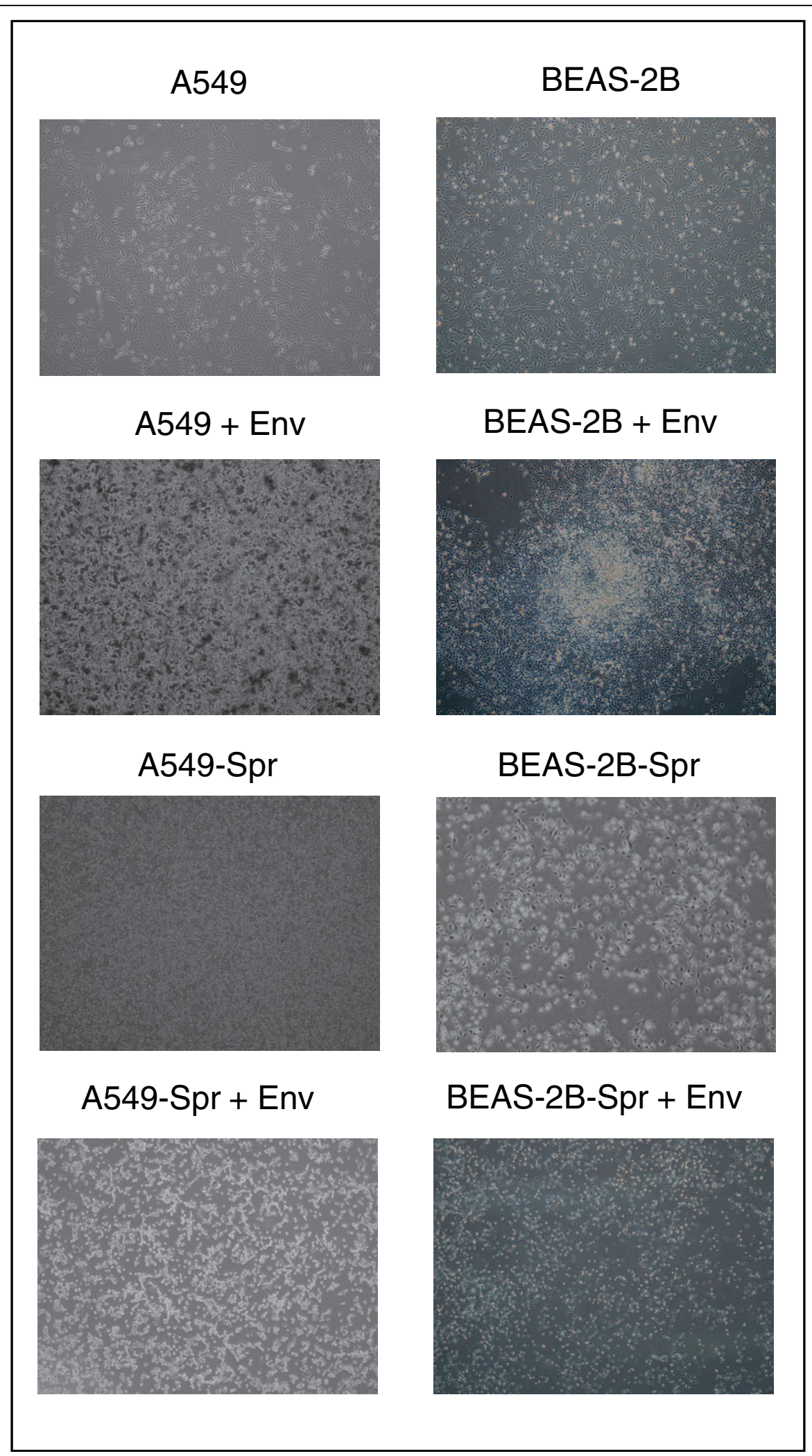

Figure 7 Sprouty2 overexpressing cells are resistant to Env-mediated transformation. A549, A549-Spr, BEAS-2B and BEAS-2B-Spr cells were transfected with the plasmid carrying Env gene by standard calcium chloride method. Foci formation after 14 days was monitored and photographed at 10x magnification. 


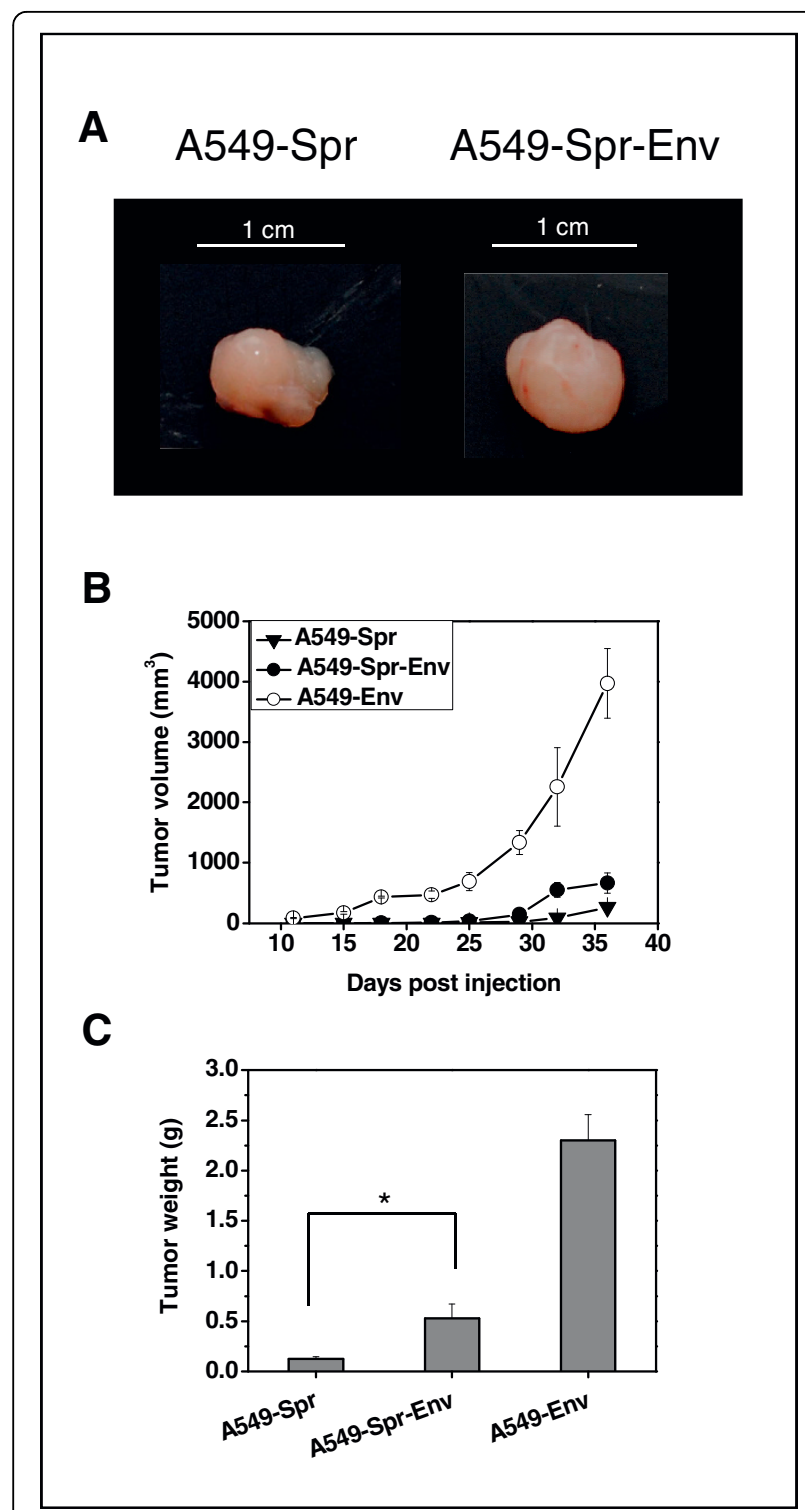

Figure 8 A549-Spr-Env cells lack enhanced tumor forming potential in vivo. (A) Pictures of in vivo tumors formed by A549-Spr and A549-Spr-Env cells injected into the subcutaneous tissue of SCID mice and excised on day 34. (B) Growth rates of the tumors formed by the respective cell lines in SCID mice represented as tumor volume monitored for up to 5 weeks. (C) Average weight of tumors resected from SCID mice 34 days after injection. ( ${ }^{*} \mathrm{P}=$ 0.0369).

pathways, subsequently altering the biochemical status of the cells to make them resistant to oncogenic transformation.

\section{Conclusions}

Proliferation and invasion functions can be governed by distinct signaling pathways in the cells and therefore can be evoked independently in the target cells. Oncogenic Env from JSRV and the tumor suppressor human
Sprouty2 participate in overlapping signal transduction pathways and therefore are capable of influencing each other, determining the susceptibility of target cells to oncogenic transformation. Both play very relevant roles in cancer induction, progression and invasion. Sprouty2 has a clear role in cell migration, invasion and tumor formation, and its $\mathrm{Y} 55$ residue plays a crucial role in its functionality. Sprouty2 shows distinct potential for being exploited as an anti-cancer therapeutic agent for tumor regression and inhibition of cancer invasion and metastasis.

\section{Methods}

Cell culture

A549, lung adenocarcinoma cell line and its transformants were maintained in Dulbecco's modified Eagle's medium with high glucose $(4.5 \mathrm{~g} / \mathrm{L})$ supplemented with $10 \%$ bovine serum, $2 \mathrm{mM}$ L-glutamine, 100 units $/ \mathrm{ml}$ penicillin and 100 units $/ \mathrm{ml}$ streptomycin (Invitrogen, CA, USA) in a $5 \% \mathrm{CO}_{2}$ humidified incubator at $37^{\circ} \mathrm{C}$. Both stable and transient transfections were done by standard calcium chloride method, unless otherwise indicated. Cells were grown to $80 \%$ confluency in a 10 $\mathrm{cm}$ dish and were transfected with the plasmids carrying Sprouty or JSRV Env genes. In short, $28 \mu \mathrm{g}$ of plasmid DNA was mixed with $86.8 \mu \mathrm{l}$ of $2 \mathrm{M} \mathrm{CaCl}_{2}$ solution and the volume was adjusted to $600 \mu \mathrm{l}$ with sterile distilled water. This solution was added dropwise with constant stirring to equal volume of HEPES buffered saline $(0.28$ $\mathrm{M} \mathrm{NaCl}, 0.05 \mathrm{M}$ HEPES, $1.5 \mathrm{mM} \mathrm{Na} \mathrm{HPO}_{4}, \mathrm{pH} 7.0$ ) and the resultant suspension was added to the cells and incubated overnight. Fresh medium was replaced in the morning. A549 and BEAS-2B cells were stably transformed with pCDNA 3.1(-)-Sprouty2 to create A549-Spr and BEAS-2B-Spr cell lines that overexpressed Sprouty2. A549 was transfected with Sprouty2 mutants to create A549-Y55FSpr and A549-Y227FSpr cell lines. A549 and BEAS-2B cells were transfected with pBS-Env and the stable clones were selected from the foci of transformed cells, and developed into A549-Env and BEAS-2B-Env cell lines. Env-transformed cells were selected based on their foci forming ability and serum independence as described previously $[9,75]$. Wild type or mutant Sprouty-transformed cells were selected with $600 \mu \mathrm{g} / \mathrm{ml}$ of G418 (Sigma-Aldrich, St Louis, MO, USA). BEAS-2B, lung epithelial cell line was maintained in LHC-9 medium (Invitrogen) supplemented with 100 units/ml penicillin and 100 units/ml streptomycin and maintained as above.

\section{Plasmids and primers}

Full length of JSRV Envelope gene [Genbank:AF105220] (nucleotides 5348 to 7195 ) cloned in pBluescript (KS ${ }^{-}$) vector under CMV promoter was gifted by Hung Fan, 


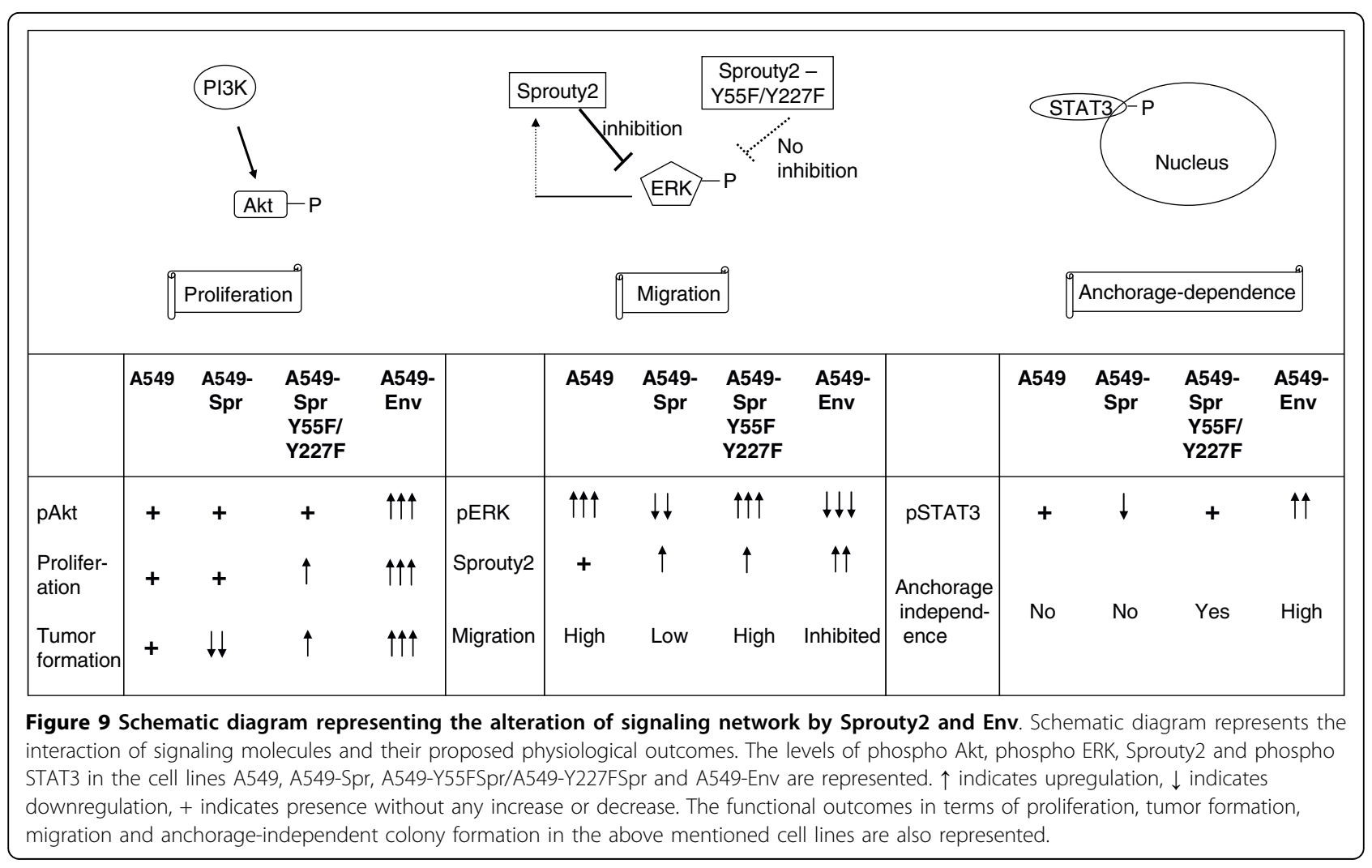

University of California, Irvine, USA. Full length cDNA of human Sprouty2 gene was cloned by RT-PCR from A549 cell line using the following primers, forward: GGGAATTCCCAAGACCTGATGGAGGCCAG and reverse: CAGGGATCCCTATGTTGGTTTTTCAAAG TTCCTAG as described previously [33] into the expression vector pCDNA3.1(-) using EcoR1 and BamH1 restriction enzymes. The PCR conditions were: $45^{\circ} \mathrm{C}$ for $30 \mathrm{~min}, 94^{\circ} \mathrm{C}$ for $5 \mathrm{~min}$; followed by 35 cycles of $94^{\circ} \mathrm{C}$ for $45 \mathrm{sec}, 59^{\circ} \mathrm{C}$ for $45 \mathrm{sec}$ and $72^{\circ} \mathrm{C}$ for $75 \mathrm{sec}$; followed by $72^{\circ} \mathrm{C}$ for $7 \mathrm{~min}$. The dominant negative mutants of Sprouty2, Y55F and Y227F were created by site-directed mutagenesis by PCR using Pfu DNA polymerase and the following primers. Y55F forward: CCGAAACACCAATGAGTTCACAGAGG, Y55F reverse: CCTCTGTGAA CTCATTGGTGTTTCGG, Y227F forward: GGTCTC TTCTTT CACTGTTCTAATG and Y227F reverse: CATTAGAACAGTGAAAGAAGAGACC. PCR conditions for creation of Y55F mutant were: $94^{\circ} \mathrm{C}$ for $5 \mathrm{~min}$; followed by 30 cycles of $94^{\circ} \mathrm{C}$ for $45 \mathrm{sec}, 55^{\circ} \mathrm{C}$ for $45 \mathrm{sec}$ and $72^{\circ} \mathrm{C}$ for $13 \mathrm{~min}$; followed by $72^{\circ} \mathrm{C}$ for $30 \mathrm{~min}$; and for Y227F mutant, $94^{\circ} \mathrm{C}$ for $5 \mathrm{~min}$; followed by 30 cycles of $94^{\circ} \mathrm{C}$ for $45 \mathrm{sec}, 52^{\circ} \mathrm{C}$ for $45 \mathrm{sec}$ and $72^{\circ} \mathrm{C}$ for $13 \mathrm{~min}$; followed by $72^{\circ} \mathrm{C}$ for $30 \mathrm{~min}$. After the PCR reaction, Dpn1 restriction enzyme was used to digest the template DNA. All the constructs were confirmed by restriction enzyme digestion and sequence analysis. All the enzymes were purchased from New England Biolabs (Ipswich, MA, USA).

\section{RT-PCR}

RNA samples were isolated from A549 cells transiently transfected with the empty vector (pBS) or Env gene cloned in $\mathrm{pBS}$ (pBS-Env). On day 3 and 6, the cell lines were treated with TRIZOL reagent (Invitrogen) and total RNA was isolated following the manufacturer's instructions. Human Sprouty 2 mRNA and $\beta$-actin mRNA were detected by reverse transcription-polymerase chain reaction (RT-PCR) analysis using one-step RT-PCR Premix reagent (iNtRON Biotechnology, Korea) and the following primers: Sprouty2 forward: 5'-CCAAGACCTGATGGAGGCCAG-3', Sprouty2 reverse: 5'TGTTGGTTTTTCAAAGTTCCTAGG-3', $\beta$-actin forward: $5^{\prime}$-TGCGTGACATTAAGG AGAAG-3' and $\beta$ actin reverse: $5^{\prime}$-CTGCATCCTGTCGGCAATG-3'. The PCR conditions were $45^{\circ} \mathrm{C}$ for $30 \mathrm{~min}, 94^{\circ} \mathrm{C}$ for $5 \mathrm{~min}$; followed by 35 cycles of $94^{\circ} \mathrm{C}$ for $45 \mathrm{sec}, 59^{\circ} \mathrm{C}$ (for Sprouty) or $56^{\circ} \mathrm{C}$ (for $\beta$-actin) for $45 \mathrm{sec}$ and $72^{\circ} \mathrm{C}$ for $75 \mathrm{sec}$, followed by incubation at $72^{\circ} \mathrm{C}$ for $7 \mathrm{~min}$.

\section{Quantitative RT-PCR}

Total RNA (2 $\mu \mathrm{g})$ isolated from the stable cell lines A549, A549-Spr and A549-Env was converted to cDNA using Superscript II reverse transcriptase enzyme and 
oligo dT primers (Invitrogen) following the manufacturer's instructions. The expression levels of hSprouty2 relative to the house keeping gene, glucose 6-phosphate dehydrogenase (G6PD) was assessed in the stable cell lines by quantitative PCR analysis of the cDNA using ABI PRISM 7900 sequence detection system using SYBR Green with the following primers: Sprouty forward: TGGC AAGTGCAAATGTAAGG and Sprouty reverse: CTTGTCGCAGATCCAGTCC, G6PD forward: GCAAACAGAGTGAGCCCTTC and G6PD reverse: GGCCAGCCACATAG GAGTT. Data were expressed using the comparative $C_{t}$ method [76] as fold increase in hSprouty 2 expression compared to the internal control, G6PD.

\section{Western Blot Analyses}

Western blot was carried out as described [16] using the SuperSignal West Pico chemiluminescent substrate (Pierce, Rockford, IL, USA) with the following antibodies against phospho Thr180/Tyr182 p38 MAPK, p38 MAPK, phospho Thr202/Tyr204 p44/42 ERK, p44/42 ERK, phospho Ser473 Akt, Akt, phospho Tyr705 STAT3, STAT3, phospho Ser380 PTEN, PTEN (Cell Signaling Technology, MA, USA), Sprouty (Upstate Biotechnology, Billerica, MA, USA), TWIST (Santa Cruz Biotechnology, CA, USA), TIMP1, TIMP2, $\beta$-actin (Abcam, Cambridge, MA, USA) followed by the appropriate secondary antibodies conjugated to HRP (Thermo Fisher Scientific, MA, USA). Cytoplasmic and nuclear extracts were prepared using NE-PER kit (Pierce) following manufacturer's instructions. For detection of secreted TIMPs, conditioned media (without FBS) obtained from the different cell lines were concentrated 20-fold using Amicon Ultra centrifugal filter devices (10 Kea) (Millipore, MA, USA) and sample corresponding to $1 \mathrm{ml}$ medium was loaded per well. The blots were quantified using Image J software (NIH, USA).

\section{MMP Zymogram}

$20 \mu \mathrm{l}$ of conditioned media (without FCS) obtained from different cell lines after $24 \mathrm{~h}$ incubation were assayed for gelatinase activity using $10 \%$ SDS-PAGE gels containing gelatin $(0.1 \% \mathrm{w} / \mathrm{v}$; Sigma-Aldrich) $[77,78]$. Gels were stained with $0.2 \%$ Coomassie brilliant blue R-250 (BioRad Laboratories, CA, USA) and destained in a solution containing $30 \%$ methanol and $10 \%$ acetic acid. Gelatinase activity was visualized as cleared regions in the blue gels.

\section{Proliferation assay}

Cells were serum starved over night and seeded $\left(1 \times 10^{5}\right.$ cells per well) in a 24- well culture plate in triplicates in DMEM medium with $10 \% \mathrm{FBS}$ and incubated at $37^{\circ} \mathrm{C}$ in a $5 \% \mathrm{CO}_{2}$ humidified incubator. After 24, 48, 72 and
96 hours, the live cell number was determined by trypan blue exclusion using a haemocytometer. When using pharmacological inhibitors, the cells were pretreated with MEK inhibitors U0126 (5 or $20 \mu \mathrm{M}$ ) or PI3K inhibitor LY294002 (5 or $20 \mu \mathrm{M}$ ) (Sigma-Aldrich) for $30 \mathrm{~min}$ and allowed to migrate in the presence of the inhibitors with periodical addition every $36 \mathrm{~h}$.

\section{Migration assay}

In vitro migration assays were performed using Corning Costar transwell supports (Corning, NY, USA) containing a gelatin-coated polycarbonate membrane filter $(6.5$ mm diameter, $8 \mu \mathrm{M}$ pore size) in a 24-well assay system. DMEM with $10 \%$ FBS was placed in the lower chamber and in the upper chamber 50,000 cells suspended in DMEM with $1 \%$ FBS were placed. The setup was kept in $5 \% \mathrm{CO} 2$ humidified incubator. After $15 \mathrm{~h}$, the migrated cells in the lower surface were fixed with $4 \%$ formaldehyde, stained with crystal violet, viewed under a microscope, photographed and counted.

When using pharmacological inhibitors, the cells were pretreated with the MEK inhibitors PD98059 $(20 \mu \mathrm{M})$ or U0126 $(20 \mu \mathrm{M})$ or the PI3K inhibitor LY294002 $(20 \mu \mathrm{M})$ for $30 \mathrm{~min}$ and then allowed to migrate in the presence of the inhibitors.

\section{siRNA to Sprouty2}

Cells were grown in a 6 -well plate to $80 \%$ confluency and transfected with 200 pico moles of human Sprouty2-specific siRNA or control siRNA (Santa Cruz Biotechnology). To $50 \bar{A} \mathrm{~L}$ of culture medium pre-mixed with $1 \bar{A} \mathrm{~L}$ of TurboFect transfection reagent (Fermentas, Maryland, USA), 200 pmoles of siRNA was added and the mixture was added per well of the 6-well plate. Cells were incubated at $37^{\circ} \mathrm{C}$ for $24 \mathrm{~h}$ and then trypsinized, counted and subjected to cell migration assay or cell lysates were prepared for Western blotting as described above.

\section{Colony formation assay}

In $60 \mathrm{~mm}$ culture dishes, $0.5 \%$ agarose in DMEM with $10 \%$ FBS was added as the base agar followed by a top layer containing 5000 cells in DMEM with $0.35 \%$ low melting agarose and 10\% FBS. DMEM with $10 \%$ FBS was overlaid on the top agar. Plates were incubated in $5 \% \mathrm{CO}_{2}$ humidified incubator for 14 days with periodical medium changes. The colonies were stained with crystal violet and counted. Triplicates were maintained for each group.

\section{Tumor cells xenografts in SCID mice}

Subcutaneous tumors were generated by injecting $1 \times$ $10^{6}$ cells in $0.1 \mathrm{ml}$ saline subcutaneously in the thighs of 7 weeks old female NOD.CB17-Prkdc ${ }^{\text {scid }}$ (SCID) mice 
purchased from the National Experimental Animal Center (Taipei, Taiwan ROC). Five to seven mice were used for each treatment and they were monitored twice weekly for tumor development, and tumor diameter was measured using calipers. Tumor volume was determined using the formula, volume $=0.52 \times($ width $) \times($ length $)$. The tumors were resected after 34 days, weighed and processed for histological analysis. All the experimental procedures were in accordance with the institutional guidelines of Animal Care and Use Committee of the Animal Facility in National Health Research Institutes.

\section{Histological analysis}

Excised tumors were fixed in $10 \%$ buffered neutral formalin solution (Sigma-Aldrich) overnight, dehydrated, embedded in paraffin (Thermo Fisher Scientific), sectioned at $4 \mu \mathrm{m}$ thickness and stained with $1 \%$ hematoxylin and eosin solution (Sigma-Aldrich). Bright field microscopy pictures were taken at $400 \times$ magnifications.

\section{Statistics}

All the experiments were repeated independently 2-5 times.

Data are presented as mean \pm SE. Differences between the groups were assessed by paired Student's $t$ test using Graphpad software.

\section{Abbreviations \\ JSRV: Jaagsiekte sheep retrovirus; Env: Envelope; PI3K: phosphatidyl inositol 3-kinase; ERK: extracellular signal regulated kinase; STAT3: signal transducer of activator of transcription 3; PTEN: phosphatase and tensin homologue; MAPK: mitogen-activated protein kinase; MMP: matrix metalloproteinase; SCID: severe combined immunodeficiency; TIMP: tissue inhibitor of metalloproteinase; HYAL2: hyaluronidase 2; MEK: mitogen-activated protein kinase/extracellular signal-regulated kinase}

\section{Acknowledgements}

This work was supported by National Health Research Institutes intramural funding 98A1-VCPP08-014.

We thank Dr. Srikumar Chakravarthi (School of Medical Sciences: Pathology, International Medical University, Malaysia) for professional comments regarding histochemistry of tumor sections.

\footnotetext{
Author details

${ }^{1}$ Vaccine R\&D Center, National Health Research Institutes, 35, Keyan Road, Zhunan, Miaoli County 350, Taiwan. ${ }^{2}$ Current Address: School of Medical Sciences, Division of Human Biology, International Medical University, Kuala Lumpur, Malaysia. ${ }^{3}$ The Graduate Division of Biological and Biomedical Sciences (GDBBS), Emory University, Atlanta, Georgia, GA 30322, USA. ${ }^{4}$ Department of Dentistry, Kaohsiung Municipal Hsiaokang Hospital, School of Dentistry, College of Dental Medicine, Kaohsiung Medical University, Kaohsiung, Taiwan. ${ }^{5}$ Graduate Program of Biotechnology in Medicine, Institute of Molecular Medicine, National Tsing Hua University, Hsinchu 300, Taiwan.
}

\section{Authors' contributions}

EC was involved in the conception and design of experiments, acquisition, analysis and interpretation of data and drafting of the manuscript. YWL and FD were involved in the design and execution of some experiments. YHC supervised the project, analysis and interpretation of data, and commented on the manuscript. All authors read and approved the final manuscript.

\section{Competing interests}

The authors declare that they have no competing interests.

Received: 31 March 2010 Accepted: 2 August 2010

Published: 2 August 2010

\section{References}

1. Maeda N, Fan H, Yoshikai Y: Oncogenesis by retroviruses: old and new paradigms. Rev Med Virol 2008, 18:387-405.

2. Maeda N, Fan H: Signal transduction pathways utilized by enzootic nasal tumor virus (ENTV-1) envelope protein in transformation of rat epithelial cells resemble those used by jaagsiekte sheep retrovirus. Virus Genes 2008, 36:147-155.

3. Wootton $\mathrm{SK}$, Halbert $\mathrm{CL}$, Miller $\mathrm{AD}$ : Sheep retrovirus structural protein induces lung tumours. Nature 2005, 434:904-907.

4. Chitra E, Yu SL, Hsiao KN, Shao HY, Sia C, Chen $I H$, Hsieh SY, Chen JH, Chow YH: Generation and characterization of JSRV envelope transgenic mice in FVB background. Virology 2009, 393:120-126.

5. Verwoerd DW, Payne AL, York DF, Myer MS: Isolation and preliminary characterization of the jaagsiekte retrovirus (JSRV). Onderstepoort J Vet Res 1983, 50:309-316.

6. Mornex JF, Thivolet F, De las Heras M, Leroux C: Pathology of human bronchioloalveolar carcinoma and its relationship to the ovine disease. Curr Top Microbiol Immunol 2003, 275:225-248.

7. Dakessian RM, Inoshima $Y$, Fan H: Tumors in mice transgenic for the envelope protein of Jaagsiekte sheep retrovirus. Virus Genes 2007, 35:73-80.

8. Maeda N, Fu W, Ortin A, de las Heras M, Fan H: Roles of the Ras-MEKmitogen-activated protein kinase and phosphatidylinositol 3-kinase-AktmTOR pathways in Jaagsiekte sheep retrovirus-induced transformation of rodent fibroblast and epithelial cell lines. J Virol 2005, 79:4440-4450.

9. Maeda N, Palmarini M, Murgia C, Fan H: Direct transformation of rodent fibroblasts by jaagsiekte sheep retrovirus DNA. Proc Natl Acad Sci USA 2001, 98:4449-4454.

10. Rai SK, Duh FM, Vigdorovich V, Danilkovitch-Miagkova A, Lerman MI Miller AD: Candidate tumor suppressor HYAL2 is a glycosylphosphatidylinositol (GPI)-anchored cell-surface receptor for jaagsiekte sheep retrovirus, the envelope protein of which mediates oncogenic transformation. Proc Natl Acad Sci USA 2001, 98:4443-4448.

11. Songyang Z, Shoelson SE, Chaudhuri M, Gish G, Pawson T, Haser WG, King F, Roberts T, Ratnofsky S, Lechleider RJ, et al: $\mathrm{SH} 2$ domains recognize specific phosphopeptide sequences. Cell 1993, 72:767-778.

12. Cousens C, Maeda N, Murgia C, Dagleish MP, Palmarini M, Fan H: In vivo tumorigenesis by Jaagsiekte sheep retrovirus (JSRV) requires Y590 in Env TM, but not full-length orfX open reading frame. Virology 2007, 367:413-421.

13. Palmarini M, Maeda N, Murgia C, De-Fraja C, Hofacre A, Fan H: A phosphatidylinositol 3-kinase docking site in the cytoplasmic tail of the Jaagsiekte sheep retrovirus transmembrane protein is essential for envelope-induced transformation of NIH 3T3 cells. J Virol 2001, 75:11002-11009.

14. Zavala G, Pretto C, Chow YH, Jones L, Alberti A, Grego E, De las Heras M, Palmarini M: Relevance of Akt phosphorylation in cell transformation induced by Jaagsiekte sheep retrovirus. Virology 2003, 312:95-105.

15. Hofacre A, Fan H: Multiple domains of the Jaagsiekte sheep retrovirus envelope protein are required for transformation of rodent fibroblasts. $J$ Virol 2004, 78:10479-10489.

16. Chitra E, Yu SL, Hsiao KN, Shao HY, Sia C, Chen IH, Hsieh SY, Chen JH, Chow $\mathrm{YH}$ : Generation and characterization of JSRV envelope transgenic mice in FVB background. Virology 2009, 393:120-6.

17. Shair MD: A closer view of an oncoprotein-tumor suppressor interaction. Chem Biol 1997, 4:791-794.

18. Yokoyama A, Somervaille TC, Smith KS, Rozenblatt-Rosen O, Meyerson M, Cleary ML: The menin tumor suppressor protein is an essential oncogenic cofactor for MLL-associated leukemogenesis. Cell 2005, 123:207-218.

19. Okumura K, Zhao M, Depinho RA, Furnari FB, Cavenee WK: Cellular transformation by the MSP58 oncogene is inhibited by its physical interaction with the PTEN tumor suppressor. Proc Natl Acad Sci USA 2005, 102:2703-2706. 
20. Casci T, Vinos J, Freeman M: Sprouty, an intracellular inhibitor of Ras signaling. Cell 1999, 96:655-665.

21. Ozaki K, Kadomoto R, Asato K, Tanimura S, Itoh N, Kohno M: ERK pathway positively regulates the expression of Sprouty genes. Biochem Biophys Res Commun 2001, 285:1084-1088.

22. Hacohen N, Kramer S, Sutherland D, Hiromi Y, Krasnow MA: sprouty encodes a novel antagonist of FGF signaling that patterns apical branching of the Drosophila airways. Cell 1998, 92:253-263.

23. Wong ES, Lim J, Low BC, Chen Q, Guy GR: Evidence for direct interaction between Sprouty and Cbl. J Biol Chem 2001, 276:5866-5875.

24. Nadeau RJ, Toher JL, Yang X, Kovalenko D, Friesel R: Regulation of Sprouty2 stability by mammalian Seven-in-Absentia homolog 2. J Cell Biochem 2007, 100:151-160.

25. Lao DH, Chandramouli S, Yusoff P, Fong CW, Saw TY, Tai LP, Yu CY, Leong HF, Guy GR: A Src homology 3-binding sequence on the $C$ terminus of Sprouty2 is necessary for inhibition of the Ras/ERK pathway downstream of fibroblast growth factor receptor stimulation. J Biol Chem 2006, 281:29993-30000.

26. Satoh T, Torii S, Nakayama K, Nishida E: CrkL is a novel target of Sprouty2 in fibroblast growth factor signaling. Genes Cells 2010.

27. Fong CW, Leong HF, Wong ES, Lim J, Yusoff P, Guy GR: Tyrosine phosphorylation of Sprouty2 enhances its interaction with c-Cbl and is crucial for its function. J Biol Chem 2003, 278:33456-33464

28. Mason JM, Morrison DJ, Bassit B, Dimri M, Band H, Licht JD, Gross I: Tyrosine phosphorylation of Sprouty proteins regulates their ability to inhibit growth factor signaling: a dual feedback loop. Mol Biol Cell 2004 15:2176-2188.

29. Hanafusa H, Torii S, Yasunaga T, Matsumoto K, Nishida E: Shp2, an SH2containing protein-tyrosine phosphatase, positively regulates receptor tyrosine kinase signaling by dephosphorylating and inactivating the inhibitor Sprouty. J Biol Chem 2004, 279:22992-22995.

30. Chandramouli S, Yu CY, Yusoff P, Lao DH, Leong HF, Mizuno K, Guy GR: Tesk1 interacts with Spry2 to abrogate its inhibition of ERK phosphorylation downstream of receptor tyrosine kinase signaling. J Biol Chem 2008, 283:1679-1691.

31. Sasaki A, Taketomi T, Kato R, Saeki K, Nonami A, Sasaki M, Kuriyama M, Saito N, Shibuya M, Yoshimura A: Mammalian Sprouty4 suppresses Rasindependent ERK activation by binding to Raf1. Nat Cell Biol 2003, 5:427-432

32. Yigzaw $Y$, Cartin L, Pierre $S$, Scholich $K$, Patel TB: The $C$ terminus of sprouty is important for modulation of cellular migration and proliferation. $J$ Biol Chem 2001, 276:22742-22747

33. Lee CC, Putnam AJ, Miranti CK, Gustafson M, Wang LM, Vande Woude GF, Gao CF: Overexpression of sprouty 2 inhibits HGF/SF-mediated cell growth, invasion, migration, and cytokinesis. Oncogene 2004, 23:5193-5202.

34. Miyoshi K, Wakioka T, Nishinakamura H, Kamio M, Yang L, Inoue M, Hasegawa M, Yonemitsu Y, Komiya S, Yoshimura A: The Sprouty-related protein, Spred, inhibits cell motility, metastasis, and Rho-mediated actin reorganization. Oncogene 2004, 23:5567-5576.

35. Lo TL, Yusoff P, Fong CW, Guo K, McCaw BJ, Phillips WA, Yang H, Wong ES, Leong HF, Zeng Q, Putti TC, Guy GR: The ras/mitogen-activated protein kinase pathway inhibitor and likely tumor suppressor proteins, sprouty 1 and sprouty 2 are deregulated in breast cancer. Cancer Res 2004, 64:6127-6136.

36. Kwabi-Addo B, Wang J, Erdem H, Vaid A, Castro P, Ayala G, Ittmann M: The expression of Sprouty1, an inhibitor of fibroblast growth factor signal transduction, is decreased in human prostate cancer. Cancer Res 2004 64:4728-4735.

37. McKie AB, Douglas DA, Olijslagers S, Graham J, Omar MM, Heer R, Gnanapragasam VJ, Robson CN, Leung HY: Epigenetic inactivation of the human sprouty2 (hSPRY2) homologue in prostate cancer. Oncogene 2005, 24:2166-2174.

38. Fong CW, Chua MS, McKie AB, Ling SH, Mason V, Li R, Yusoff $P$, Lo TL, Leung HY, So SK, Guy GR: Sprouty 2, an inhibitor of mitogen-activated protein kinase signaling, is down-regulated in hepatocellular carcinoma. Cancer Res 2006, 66:2048-2058.

39. Lee SA, Ho C, Roy R, Kosinski C, Patil MA, Tward AD, Fridlyand J, Chen X Integration of genomic analysis and in vivo transfection to identify sprouty 2 as a candidate tumor suppressor in liver cancer. Hepatology 2008, 47:1200-1210.
40. Sutterluty H, Mayer CE, Setinek U, Attems J, Ovtcharov S, Mikula M, Mikulits W, Micksche M, Berger W: Down-regulation of Sprouty2 in nonsmall cell lung cancer contributes to tumor malignancy via extracellular signal-regulated kinase pathway-dependent and -independent mechanisms. Mol Cancer Res 2007, 5:509-520.

41. Frank MJ, Dawson DW, Bensinger SJ, Hong JS, Knosp WM, Xu L, Balatoni CE, Allen EL, Shen RR, Bar-Sagi D, Martin GR, Teitell MA: Expression of sprouty2 inhibits B-cell proliferation and is epigenetically silenced in mouse and human B-cell lymphomas. Blood 2009, 113:2478-2487.

42. Mason JM, Morrison DJ, Basson MA, Licht JD: Sprouty proteins: multifaceted negative-feedback regulators of receptor tyrosine kinase signaling. Trends Cell Biol 2006, 16:45-54

43. Liu SL, Duh FM, Lerman MI, Miller AD: Role of virus receptor Hyal2 in oncogenic transformation of rodent fibroblasts by sheep betaretrovirus env proteins. J Virol 2003, 77:2850-2858

44. Gorrini C, Squatrito M, Luise C, Syed N, Perna D, Wark L, Martinato F, Sardella D, Verrecchia A, Bennett S, Confalonieri S, Cesaroni M, Marchesi F, Gasco M, Scanziani E, Capra M, Mai S, Nuciforo P, Crook T, Lough J, Amati B: Tip60 is a haplo-insufficient tumour suppressor required for an oncogene-induced DNA damage response. Nature 2007, 448:1063-1067.

45. Lamouille S, Derynck R: Oncogene and tumour suppressor: the two faces of SnoN. EMBO J 2009, 28:3459-3460.

46. Gao CF, Xie Q, Su YL, Koeman J, Khoo SK, Gustafson M, Knudsen BS, Hay R, Shinomiya N, Vande Woude GF: Proliferation and invasion: plasticity in tumor cells. Proc Natl Acad Sci USA 2005, 102:10528-10533.

47. Maeda N, Inoshima Y, Fruman DA, Brachmann SM, Fan H: Transformation of mouse fibroblasts by Jaagsiekte sheep retrovirus envelope does not require phosphatidylinositol 3-kinase. J Virol 2003, 77:9951-9959.

48. Liu SL, Miller AD: Transformation of madin-darby canine kidney epithelial cells by sheep retrovirus envelope proteins. J Virol 2005, 79:927-933.

49. Miller AD, Van Hoeven NS, Liu SL: Transformation and scattering activities of the receptor tyrosine kinase RON/Stk in rodent fibroblasts and lack of regulation by the jaagsiekte sheep retrovirus receptor, Hyal2. BMC Cancer 2004, 4:64.

50. Hanahan D, Weinberg RA: The hallmarks of cancer. Cell 2000, 100:57-70

51. Yusoff $\mathrm{P}$, Lao DH, Ong SH, Wong ES, Lim J, Lo TL, Leong HF, Fong CW, Guy GR: Sprouty2 inhibits the Ras/MAP kinase pathway by inhibiting the activation of Raf. J Biol Chem 2002, 277:3195-3201.

52. Pintucci G, Moscatelli D, Saponara F, Biernacki PR, Baumann FG, Bizekis C, Galloway AC, Basilico C, Mignatti P: Lack of ERK activation and cell migration in FGF-2-deficient endothelial cells. FASEB J 2002, 16:598-600.

53. Su F, Li H, Yan C, Jia B, Zhang Y, Chen X: Depleting MEKK1 expression inhibits the ability of invasion and migration of human pancreatic cancer cells. J Cancer Res Clin Oncol 2009, 135:1655-1663.

54. Kyo S, Sakaguchi J, Ohno S, Mizumoto Y, Maida Y, Hashimoto M, Nakamura M, Takakura M, Nakajima M, Masutomi K, Inoue M: High Twist expression is involved in infiltrative endometrial cancer and affects patient survival. Hum Pathol 2006, 37:431-438.

55. Yang J, Mani SA, Donaher JL, Ramaswamy S, Itzykson RA, Come C, Savagner P, Gitelman I, Richardson A, Weinberg RA: Twist, a master regulator of morphogenesis, plays an essential role in tumor metastasis. Cell 2004, 117:927-939.

56. Yang Z, Zhang X, Gang H, Li X, Li Z, Wang T, Han J, Luo T, Wen F, Wu X: Up-regulation of gastric cancer cell invasion by Twist is accompanied by $\mathrm{N}$-cadherin and fibronectin expression. Biochem Biophys Res Commun 2007, 358:925-930

57. Wagner EF, Nebreda AR: Signal integration by JNK and p38 MAPK pathways in cancer development. Nat Rev Cancer 2009, 9:537-549.

58. Marty B, Maire V, Gravier E, Rigaill G, Vincent-Salomon A, Kappler M, Lebigot I, Djelti F, Tourdès A, Gestraud P, Hupé P, Barillot E, Cruzalegui F, Tucker GC, Stern MH, Thiery JP, Hickman JA, Dubois T: Frequent PTEN genomic alterations and activated phosphatidylinositol 3-kinase pathway in basal-like breast cancer cells. Breast Cancer Res 2008, 10:R101.

59. Yuan TL, Cantley LC: PI3K pathway alterations in cancer: variations on a theme. Oncogene 2008, 27:5497-5510.

60. Vazquez F, Grossman SR, Takahashi Y, Rokas MV, Nakamura N, Sellers WR: Phosphorylation of the PTEN tail acts as an inhibitory switch by preventing its recruitment into a protein complex. J Biol Chem 2001, 276:48627-48630. 
61. Cully M, You H, Levine AJ, Mak TW: Beyond PTEN mutations: the PI3K pathway as an integrator of multiple inputs during tumorigenesis. Nat Rev Cancer 2006, 6:184-192.

62. Davies MA, Lu Y, Sano T, Fang X, Tang P, LaPushin R, Koul D, Bookstein R, Stokoe D, Yung WK, Mills GB, Steck PA: Adenoviral transgene expression of MMAC/PTEN in human glioma cells inhibits Akt activation and induces anoikis. Cancer Res 1998, 58:5285-5290.

63. Uttamsingh S, Zong CS, Wang LH: Matrix-independent activation of phosphatidylinositol 3-kinase, Stat3, and cyclin A-associated Cdk2 is essential for anchorage-independent growth of v-Ros-transformed chicken embryo fibroblasts. J Biol Chem 2003, 278:18798-18810.

64. Senga T, Iwamoto T, Humphrey SE, Yokota T, Taparowsky EJ, Hamaguchi M: Stat3-dependent induction of BATF in M1 mouse myeloid leukemia cells. Oncogene 2002, 21:8186-8191.

65. Overall CM, Kleifeld O: Tumour microenvironment - opinion: validating matrix metalloproteinases as drug targets and anti-targets for cancer therapy. Nat Rev Cancer 2006, 6:227-239.

66. Bloomston M, Shafii A, Zervos E, Rosemurgy AS: TIMP-1 antisense gene transfection attenuates the invasive potential of pancreatic cancer cells in vitro and inhibits tumor growth in vivo. Am J Surg 2005, 189:675-679.

67. Chen YS, Langhammer T, Westhofen M, Lorenzen J: Relationship between matrix metalloproteinases MMP-2, MMP-9, tissue inhibitor of matrix metalloproteinases-1 and IL-5, IL-8 in nasal polyps. Allergy 2007, 62:66-72.

68. Rubin C, Zwang Y, Vaisman N, Ron D, Yarden Y: Phosphorylation of carboxyl-terminal tyrosines modulates the specificity of Sprouty-2 inhibition of different signaling pathways. J Biol Chem 2005, 280:9735-9744.

69. Sasaki A, Taketomi T, Wakioka T, Kato R, Yoshimura A: Identification of a dominant negative mutant of Sprouty that potentiates fibroblast growth factor- but not epidermal growth factor-induced ERK activation. J Biol Chem 2001, 276:36804-36808.

70. Lim J, Yusoff P, Wong ES, Chandramouli S, Lao DH, Fong CW, Guy GR: The cysteine-rich sprouty translocation domain targets mitogen-activated protein kinase inhibitory proteins to phosphatidylinositol 4,5bisphosphate in plasma membranes. Mol Cell Biol 2002, 22:7953-7966.

71. Taniguchi K, Ishizaki T, Ayada T, Sugiyama Y, Wakabayashi Y, Sekiya T, Nakagawa R, Yoshimura A: Sprouty4 deficiency potentiates Rasindependent angiogenic signals and tumor growth. Cancer Sci 2009, 100:1648-1654.

72. Hunter T: Oncoprotein networks. Cell 1997, 88:333-346.

73. Marte BM, Rodriguez-Viciana P, Wennstrom S, Warne PH, Downward J: RRas can activate the phosphoinositide 3-kinase but not the MAP kinase arm of the Ras effector pathways. Curr Biol 1997, 7:63-70.

74. Rodriguez-Viciana P, Warne PH, Vanhaesebroeck B, Waterfield MD, Downward J: Activation of phosphoinositide 3-kinase by interaction with Ras and by point mutation. EMBO J 1996, 15:2442-2451.

75. Allen TE, Sherrill KJ, Crispell SM, Perrott MR, Carlson JO, DeMartini JC: The jaagsiekte sheep retrovirus envelope gene induces transformation of the avian fibroblast cell line DF-1 but does not require a conserved SH2 binding domain. J Gen Virol 2002, 83:2733-2742.

76. Livak KJ, Schmittgen TD: Analysis of relative gene expression data using real-time quantitative PCR and the 2(-Delta Delta C(T)) Method. Methods 2001, 25:402-408.

77. Heussen C, Dowdle EB: Electrophoretic analysis of plasminogen activators in polyacrylamide gels containing sodium dodecyl sulfate and copolymerized substrates. Anal Biochem 1980, 102:196-202.

78. Fernandez-Resa P, Mira E, Quesada AR: Enhanced detection of casein zymography of matrix metalloproteinases. Anal Biochem 1995, 224:434-435.

doi:10.1186/1742-4690-7-62

Cite this article as: Chitra et al.: Functional interaction between Env oncogene from Jaagsiekte sheep retrovirus and tumor suppressor Sprouty2. Retrovirology 2010 7:62.

\section{Submit your next manuscript to BioMed Central and take full advantage of:}

- Convenient online submission

- Thorough peer review

- No space constraints or color figure charges

- Immediate publication on acceptance

- Inclusion in PubMed, CAS, Scopus and Google Scholar

- Research which is freely available for redistribution

Submit your manuscript at www.biomedcentral.com/submit 